\title{
The effects of statins on dental and oral health: a review of preclinical and clinical studies
}

\author{
Shabnam Tahamtan ${ }^{1}$, Farinaz Shirban ${ }^{1}$, Mohammad Bagherniya², Thomas P. Johnston ${ }^{3}$ \\ and Amirhossein Sahebkar ${ }^{4,5,6,7^{*}}$
}

\begin{abstract}
The statin family of drugs are safe and effective therapeutic agents for the treatment of arteriosclerotic cardiovascular disease (CVD). Due to a wide range of health benefits in addition to their cholesterol lowering properties, statins have recently attracted significant attention as a new treatment strategy for several conditions, which are not directly related to normalizing a lipid profile and preventing CVD. Statins exert a variety of beneficial effects on different aspects of oral health, which includes their positive effects on bone metabolism, their anti-inflammatory and antioxidant properties, and their potential effects on epithelization and wound healing. Additionally, they possess antimicrobial, antiviral, and fungicidal properties, which makes this class of drugs attractive to the field of periodontal diseases and oral and dental health. However, to the best of our knowledge, there has been no comprehensive study to date, which has investigated the effects of statin drugs on different aspects of dental and oral health. Therefore, the primary objective of this paper was to review the effect of statins on dental and oral health. Results of our extensive review have indicated that statins possess remarkable and promising effects on several aspects of dental and oral health including chronic periodontitis, alveolar bone loss due to either extraction or chronic periodontitis, osseointegration of implants, dental pulp cells, orthodontic tooth movement, and orthodontic relapse, tissue healing (wound/bone healing), salivary gland function, and finally, anti-cancer effects. Hence, statins can be considered as novel, safe, inexpensive, and widely-accessible therapeutic agents to improve different aspects of dental and oral health.
\end{abstract}

Keywords: Statin, Periodontal disease, Dental health, Oral health, Therapeutic agent

\section{Introduction}

The burden of oral diseases such as dental caries, periodontal diseases, tooth loss, lesions of the oral mucosa including those resulting from trauma, oropharyngeal cancers, and oral disease associated with human immunodeficiency virus/acquired immunodeficiency syndrome (HIV/AIDS), is very high in both developing and developed countries and is considered a major public health concern globally [1-3]. It has been recently

\footnotetext{
*Correspondence: sahebkara@mums.ac.ir; amir_saheb2000@yahoo.com ${ }^{7}$ Department of Medical Biotechnology, School of Medicine, Mashhad University of Medical Sciences, P.O. Box: 91779-48564 Mashhad, Iran

Full list of author information is available at the end of the article
}

reported that the total cost of treatment of dental diseases was $\$ 544.41$ billion worldwide in 2015 [4]. One of the most prevalent conditions is periodontal disease, which affects approximately $20-50 \%$ of the global population [5]. Moreover, systemic diseases such as cardiovascular disease (CVD), diabetes, and adverse pregnancy outcomes are often associated with periodontal disease [5-9]. Therefore, incorporation of preventative strategies for oral diseases is crucial, particularly because reducing the incidence of oral and periodontal diseases can lead to a reduction in various systemic diseases. Considering the fact that general health and quality of life are profoundly affected by oral health and the very high prevalence of oral and dental diseases, finding new, effective, and safe 
therapeutic agents to increase oral health is definitely indispensable [5, 10-13].

The statin family of drugs represent safe and effective therapeutic agents to reduce cholesterol biosynthesis in the liver and reduction of the levels of low-density lipoprotein cholesterol (LDL-C), which are causally associated with arteriosclerotic cardiovascular disease [14-20].

Beyond their potent lipid-lowering effect, which reduces both cardiovascular risk and mortality, it is reported that statins have several promising effects on human health. These pleiotropic effects include improved endothelial function, anti-inflammatory, antioxidant properties, immunomodulatory action, and anti-thrombotic effects [21-29]. Recently, a growing body of evidence suggest that statins might have promising effects on oral and dental health through different mechanisms (Fig. 1). For example, it has been well-documented that statins exert anabolic effects on bone metabolism in different ways. Statins stimulate differentiation of osteoblastic bone marrow stem cells by increasing the gene expression of bone morphogenic protein-2 (BMP-2). They also increase bone formation by inhibiting the apoptosis of osteoblasts [30]. Bone is constantly undergoing remodeling, and it is known that statins inhibit osteoclastic bone activity during high bone turnover, which inhibits bone resorption [24, 31]. Moreover, Statin drugs also inhibit enzymes involved with the degradation of tissue [i.e., matrix metalloproteinases (MMPs)] and improve epithelization and wound healing [24, 32, 33]. Statins also exert an effect on dentin and pulp regeneration [34-36]. As it pertains to various oral cancers, statins can also inhibit the growth, invasion, metastasis, cellular proliferation and differentiation, and cell cycle regulation of tumor cells $[37,38]$.

Antimicrobial, antiviral, and fungicidal properties are some of the other therapeutic benefits of statins $[39,40]$. The antibacterial effects of statins against certain microorganisms, including periodontal pathogens, have been reported [41, 42]. Therefore, the antimicrobial effects of statins, as well as their

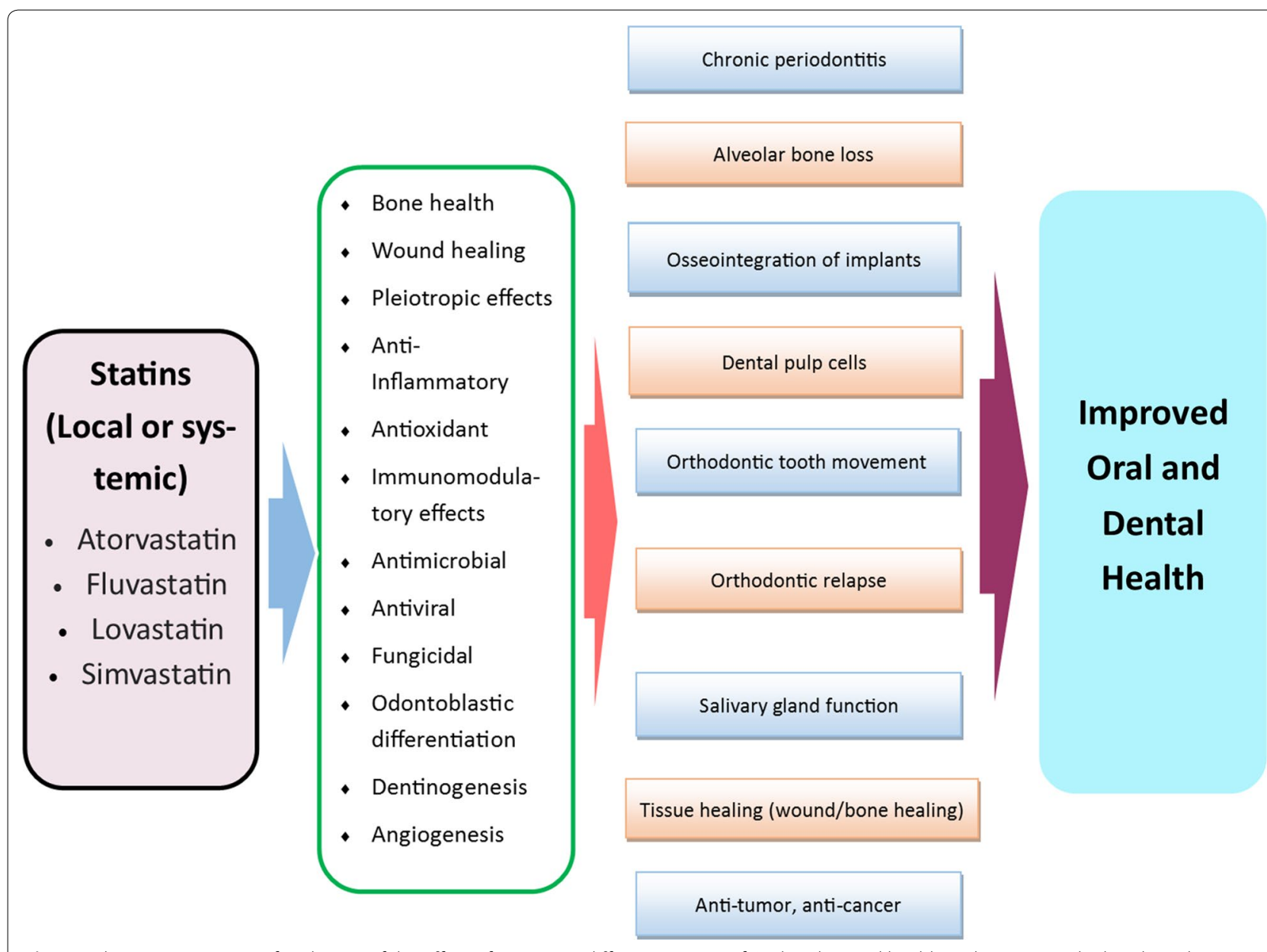

Fig. 1 Schematic summary of pathways of the effect of Statins on different aspects of Oral and Dental health and its potential related mechanisms 
anti-inflammatory, immunomodulatory, anticancer, wound healing and bone-forming properties have justified their relevance in periodontology for both the prevention of alveolar bone loss and in periodontal therapy as an adjunct to scaling and root planing (SRP) $[43,44]$. Furthermore, modulation of bone formation and inflammation by statins can affect orthodontic tooth movement (OTM) and orthodontic relapse [45, 46]. Bone modulation properties of Statins also had promising effects on osseointegration of implants in animal studies [47].

Considering the potential beneficial effects of statins on oral diseases, to the best of the authors' knowledge, there is no conclusive study that summarizes the aforementioned findings of previous studies regarding the association between statins and various aspects of oral health. Thus, the primary objective of this review was to evaluate recent pre-clinical and clinical studies investigating the effect of statins on different aspects of dental and oral health. Secondary objectives associated with this review were to report the drug delivery strategies used for statins and the drug concentrations employed.

\section{Materials and methods}

The reporting of this narrative review has been conducted in accordance with the PRISMA guidelines. A systematic electronic search of the Web of Science, Medline, SCOPUS and Google Scholar databases were using the following search terms in titles and abstracts: Periodontitis OR periodontal disease OR alveolar bone loss OR periodontal attachment loss OR periodontal pocket OR oral health OR oral diseases OR dental diseases OR oral cancer AND simvastatin OR statin OR rosuvastatin OR atorvastatin OR cerivastatin OR mevastatin OR lovastatin OR pravastatin OR Fluvastatin OR pitavastatin OR Hydroxymethylglutaryl-CoA Reductase Inhibitors. The literature was searched from January 1990 to March 2019 and only articles published in English were included. After the initial electronic search and a careful independent screening of the titles and abstracts by two researchers (FS and MB), a total of 69 papers were considered for possible inclusion. Retrieval of the 69 abstracts led to 68 full-text articles being selected. From these 69 studies, 20 studies were excluded because they were molecular in vitro studies. Studies were included if they were conducted on animal or human subjects. The methods used to ascertain the effectiveness of statins are presented for each study in the tables contained in this review. Only results that reached statistical significance have been reported (i.e., $\mathrm{p}<0.05$ ).

\section{Results}

The effect of statins on chronic periodontitis

The effectiveness of statins on chronic periodontitis has been reported in 6 systematic reviews and meta-analysis studies (Table 1). Three studies evaluated both local and systemic use of statins [32, 44, 48], while in three other studies, only local delivery of statins was investigated [43, $49,50]$.

\section{Statins as an adjunct to non-surgical periodontal treatment}

All six studies evaluated the effect of statins as an adjunct to non-surgical periodontal treatment [scaling and root planing therapy (SRP)].

All of the studies showed that SRP + statin treatment resulted in a statistically significant improvement in periodontal parameters such as an increase in clinical attachment level $(\mathrm{CAL})$, a reduction in the probing pocket depth (PD), a lower sulcus bleeding index, and a reduction in the intrabony defect depth [32, 43, 44, 48-50].

One of the studies reported that local, but not systemic statin use, caused a significantly greater gain in the clinical attachment level, less residual probing pocket depth (PD), radiographic defect depth (RDD), and reduction in the bleeding index [32].

Two studies revealed that the type of statin used was associated with periodontal outcomes. One study reported rosuvastatin as the most effective [32], while another study reported statistically significant effects with atorvastatin [44].

\section{Statins as an adjunct to surgical periodontal treatment}

Two studies evaluated the effectiveness of statins as an adjunct therapy to surgical treatment. These studies reported that the use of statins together with surgical treatment of intrabony defects resulted in significant improvement in clinical parameters such as residual PD and gain in CAL (Table 2) [32, 44].

The results of the present review show that, in general, statin treatment produces a positive effect on various parameters of periodontal tissue. These findings are supported by positive clinical results after the local application of statins during nonsurgical and surgical periodontal procedures. The rationale supporting the use of statins in treating periodontal disease is based on their antimicrobial [41, 51], anti-inflammatory [52-55], and bone-promoting properties [24, 56-58]. In particular, statins have been shown to exert antimicrobial effects against A. actinomycetemcomitans and Porphyromonas gingivalis. Both bacteria are implicated in the pathogenesis of periodontitis $[41,51]$. Furthermore, statins inhibit enzymes involved with the degradation of tissue (e.g., matrix metalloproteinases) and exert a proliferative effect on mesenchymal stromal cells and endothelial progenitor 


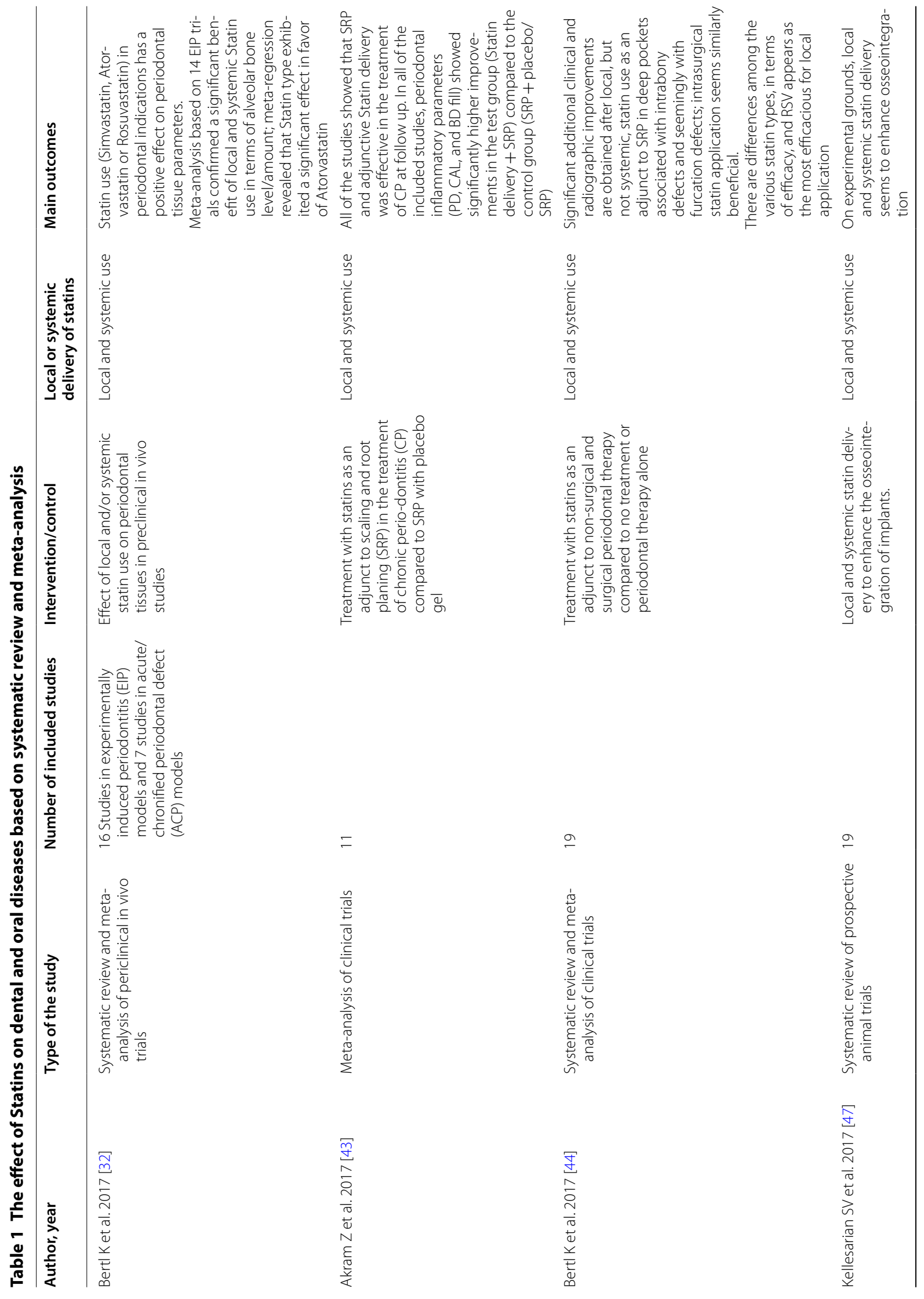




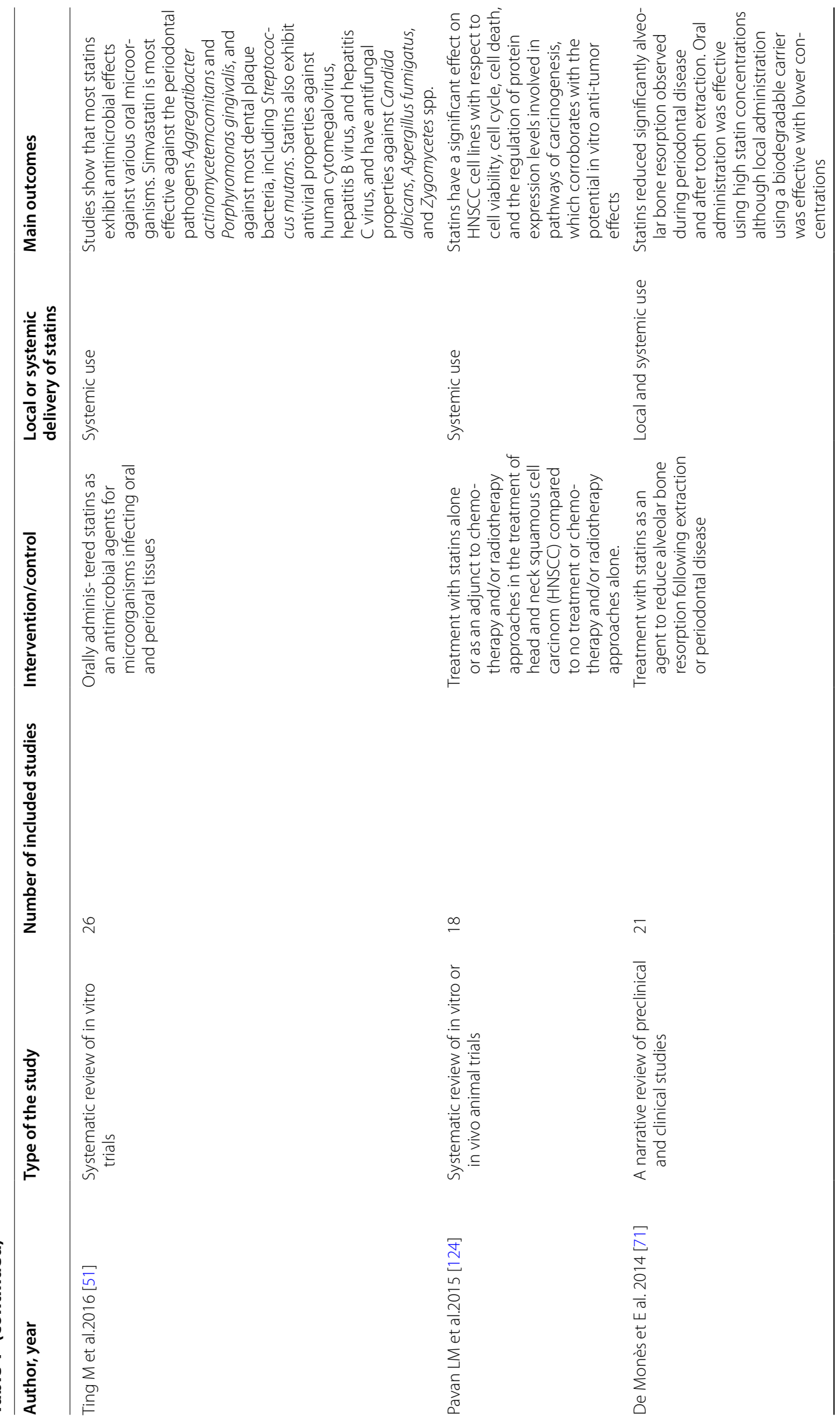




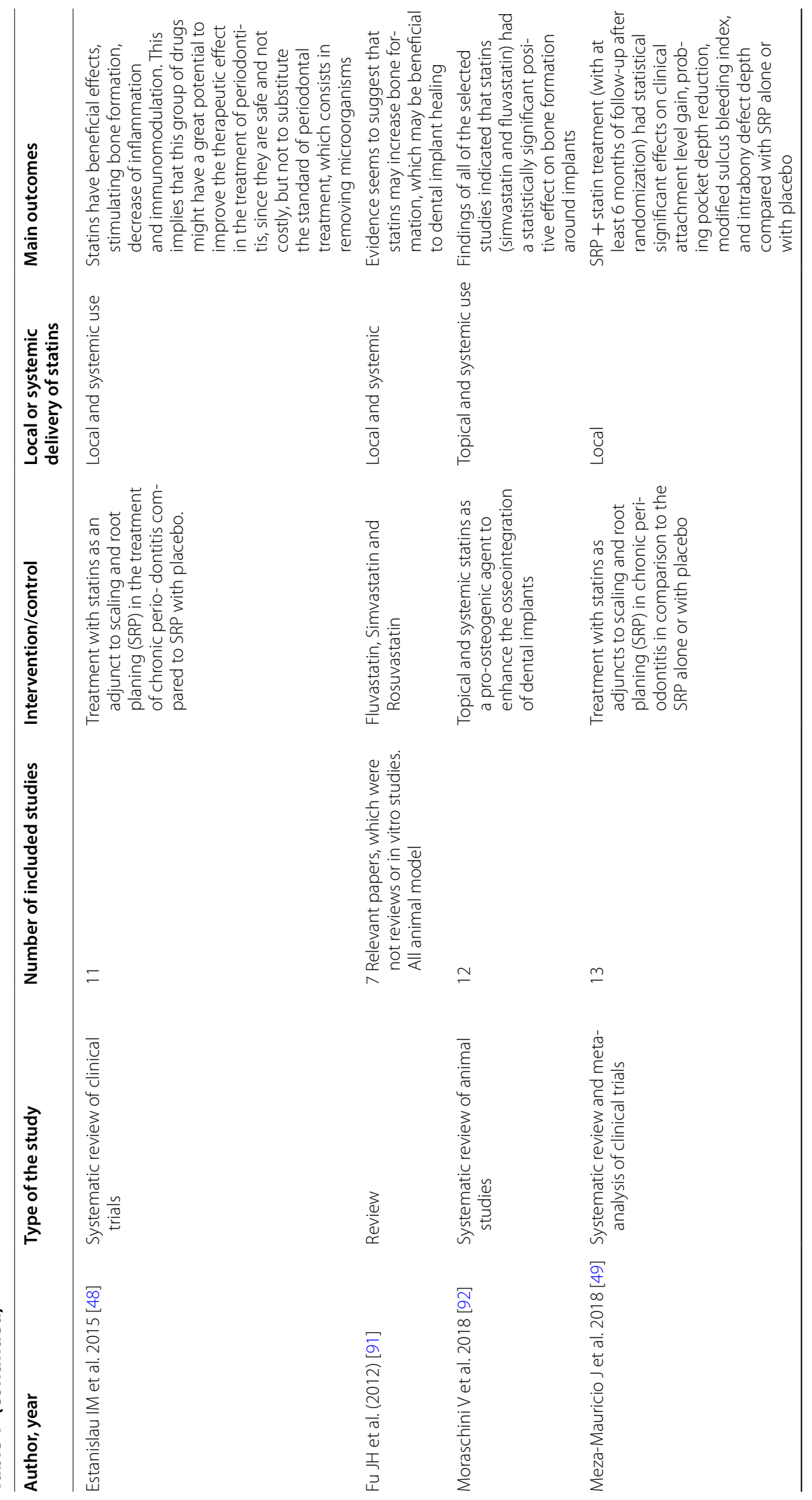




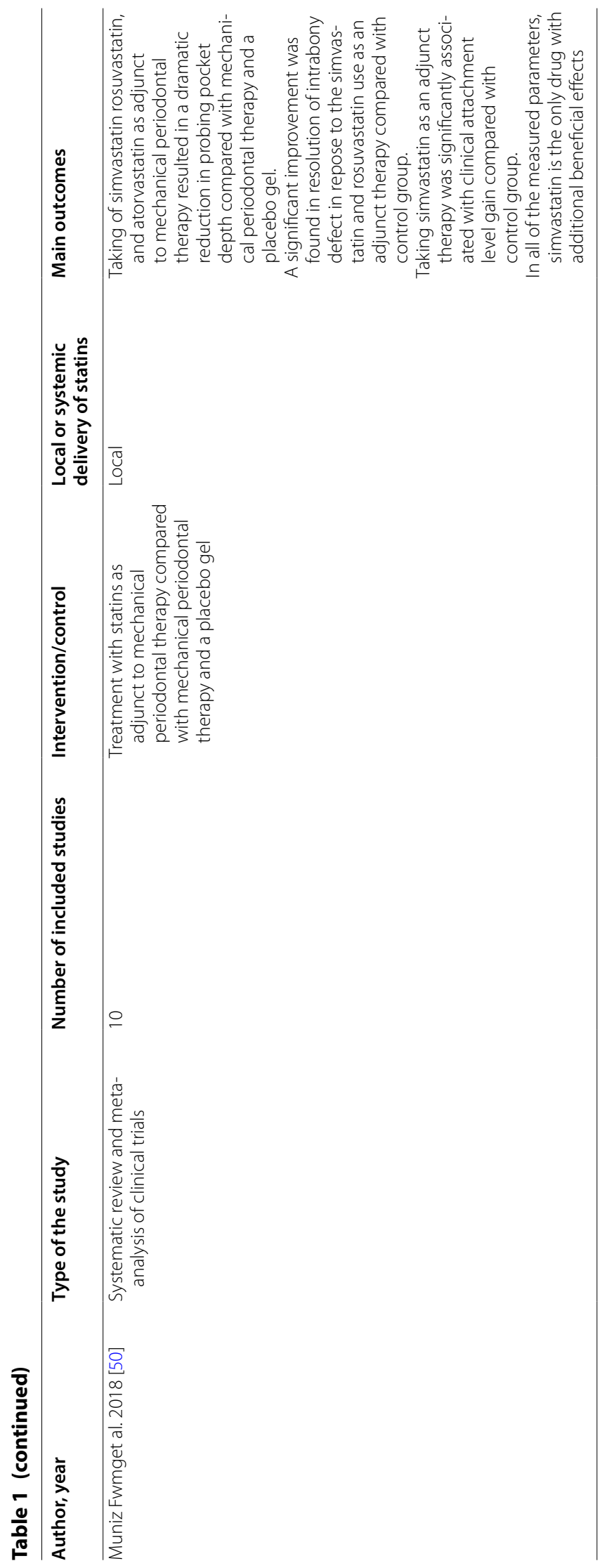




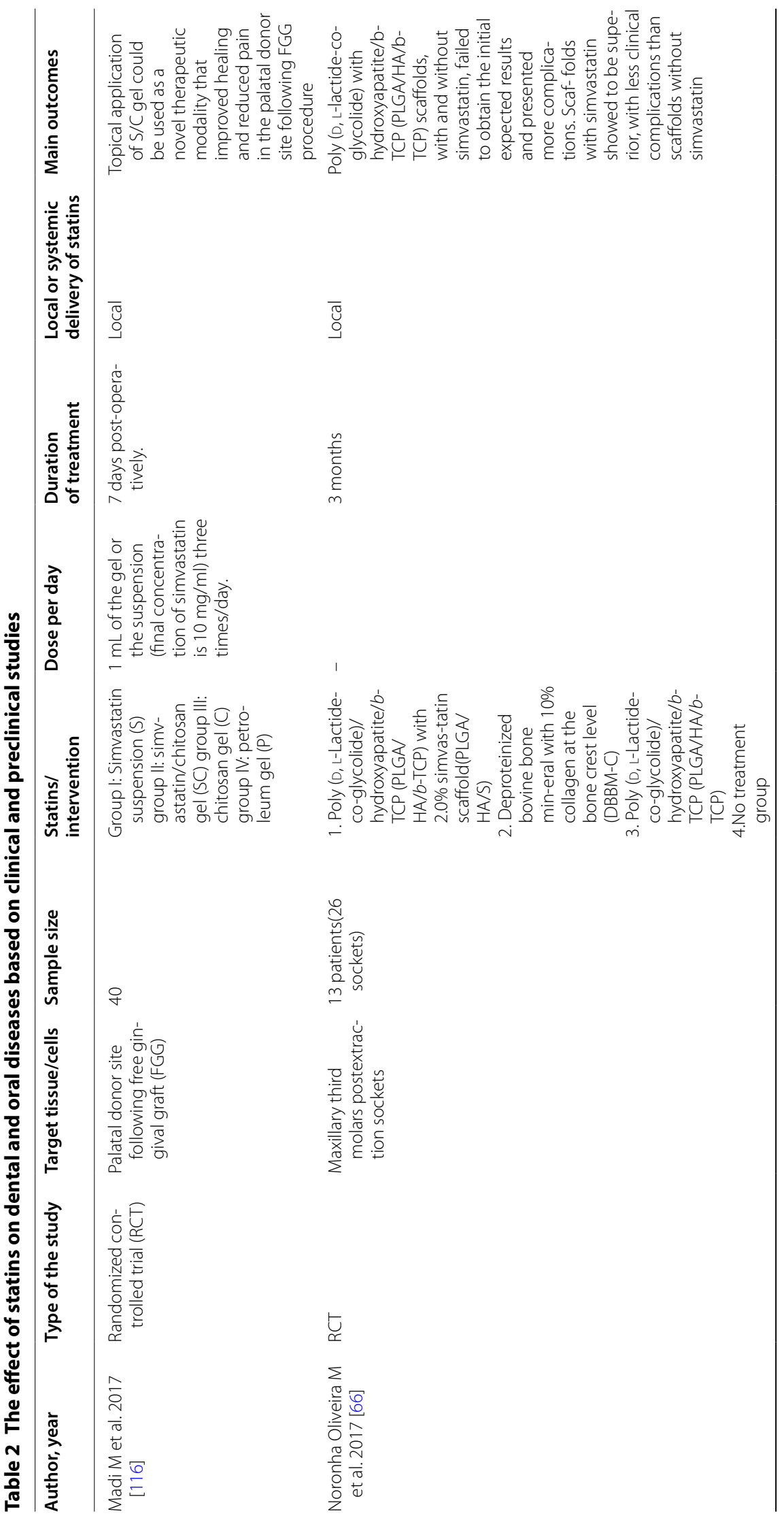




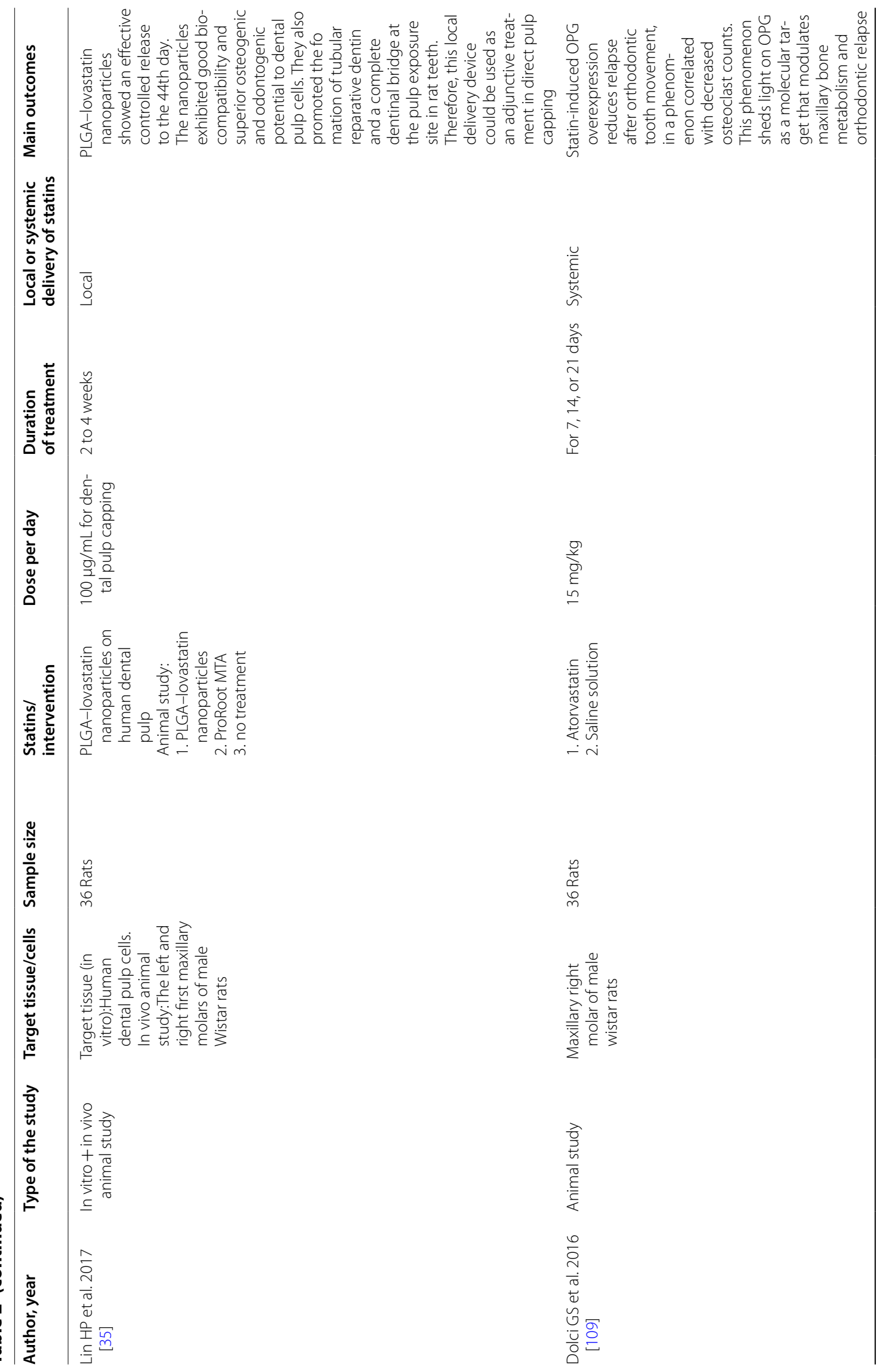




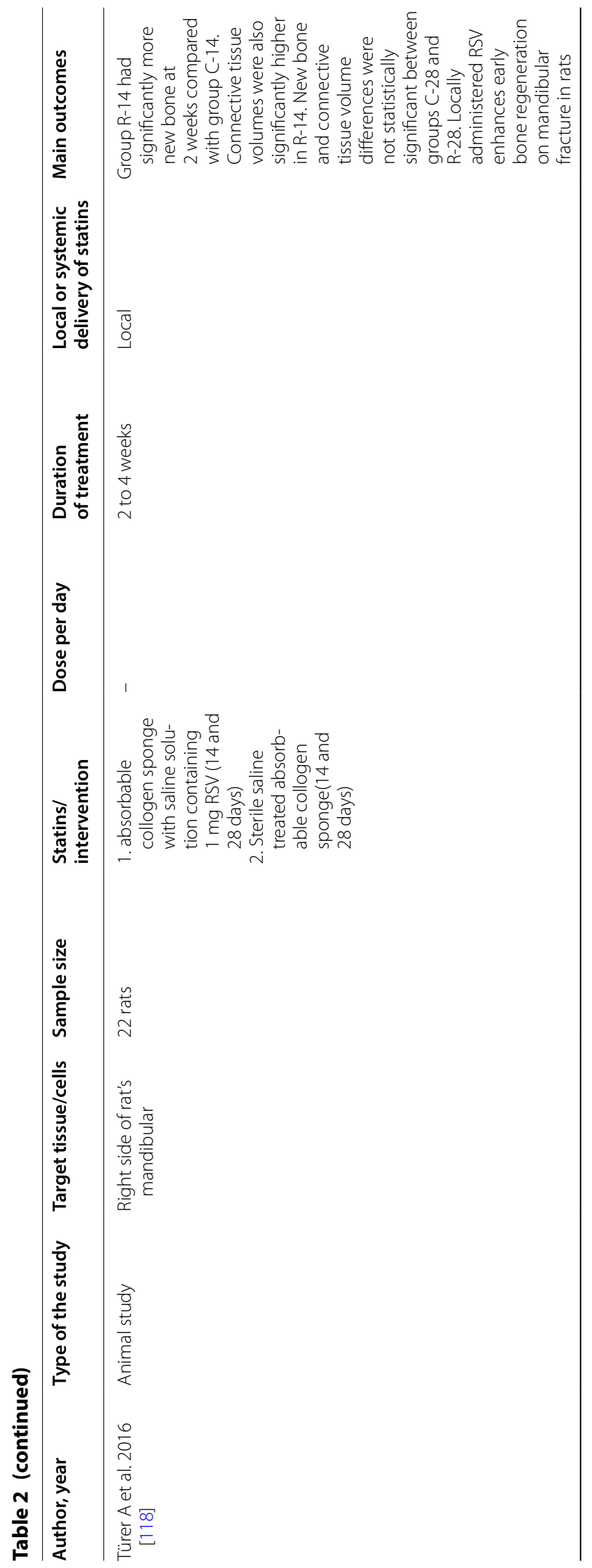




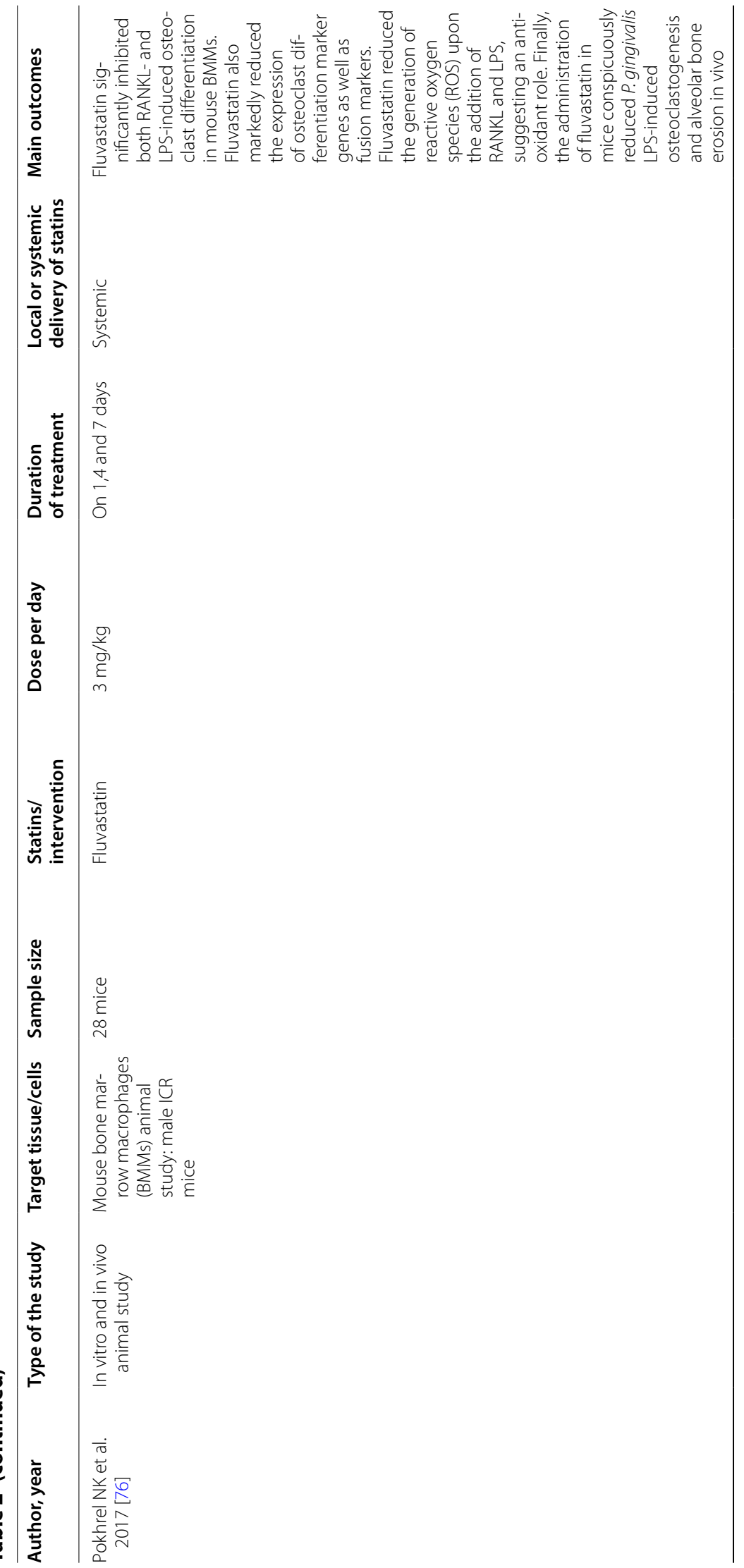




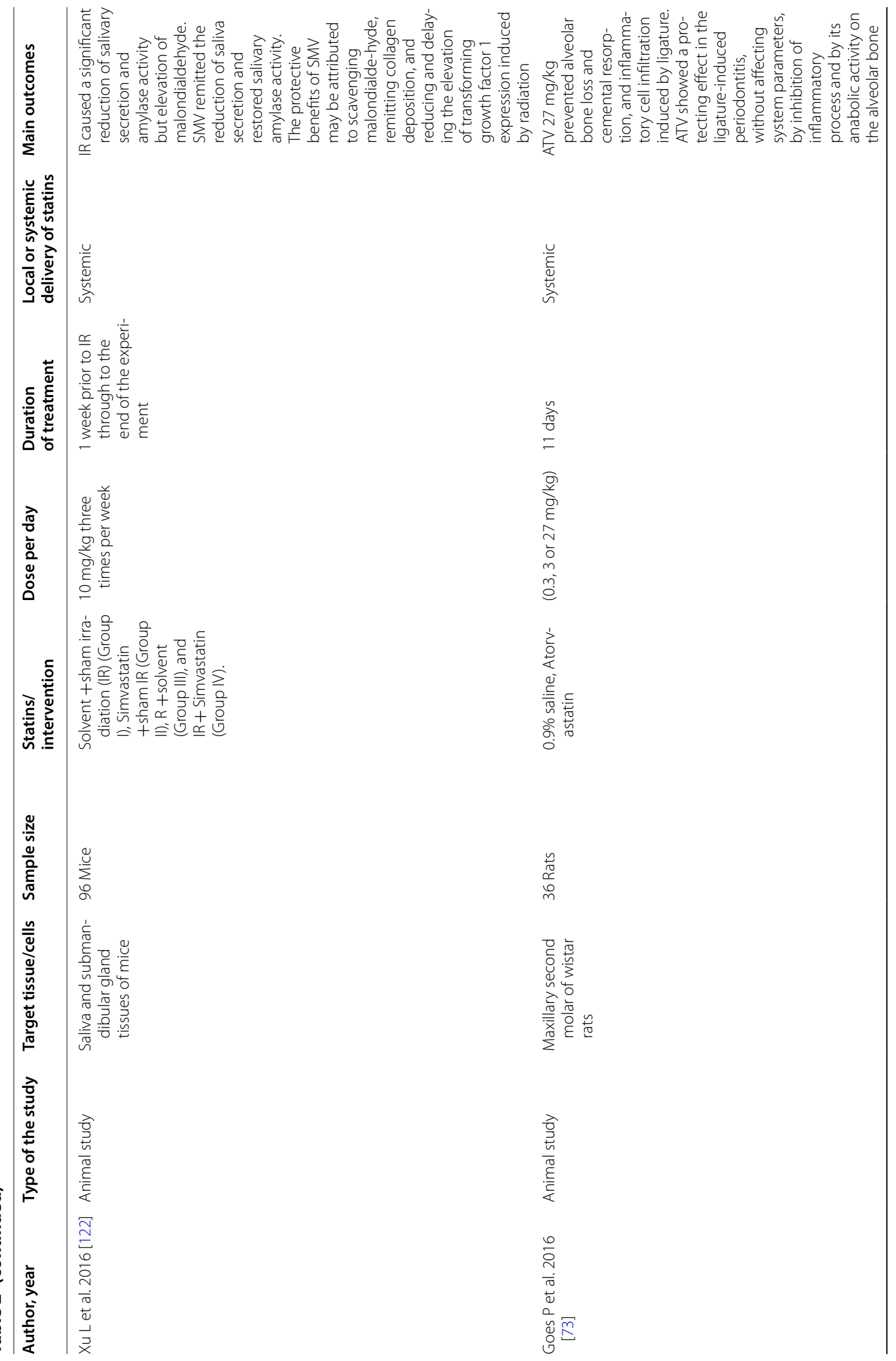




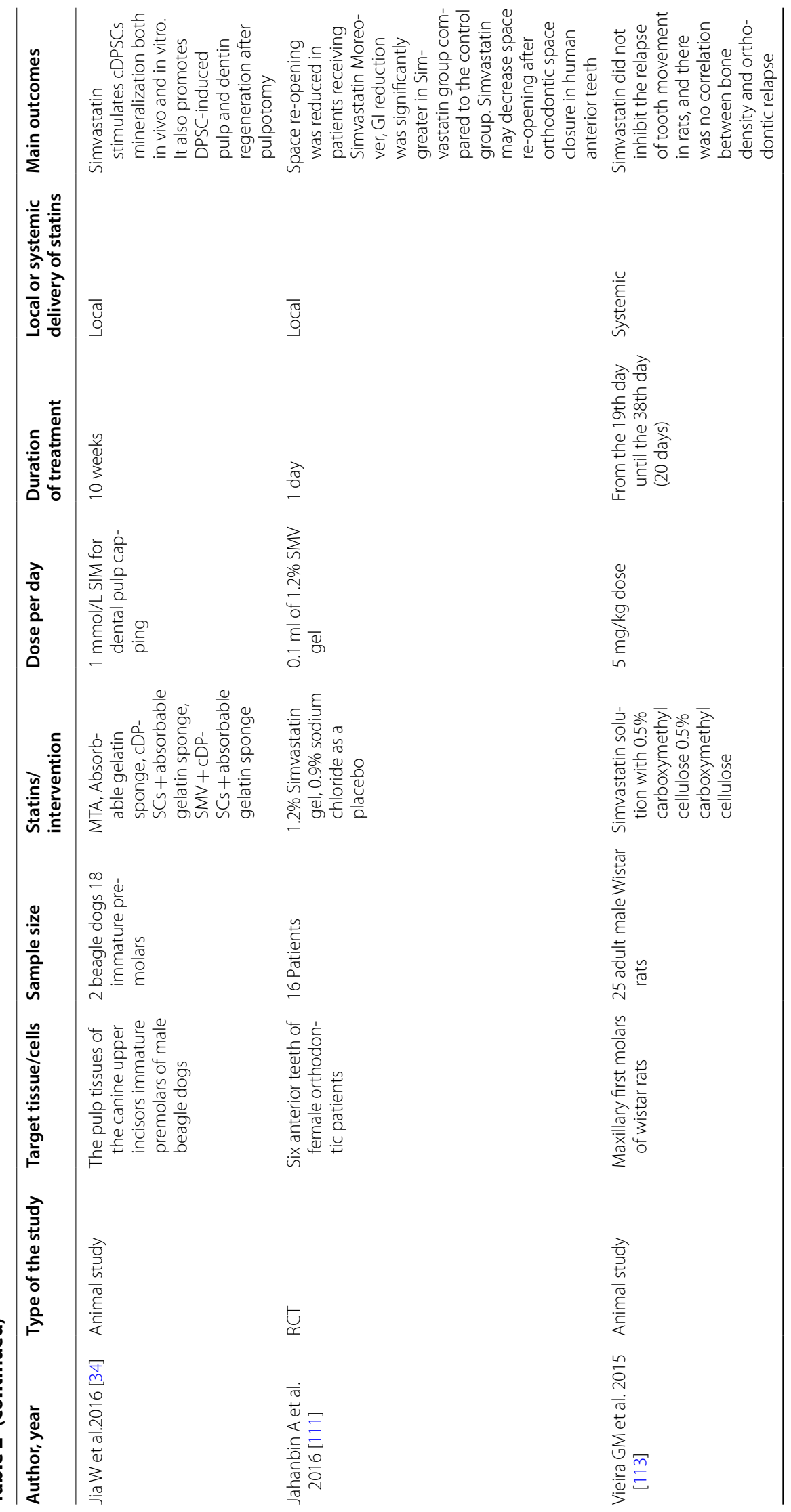




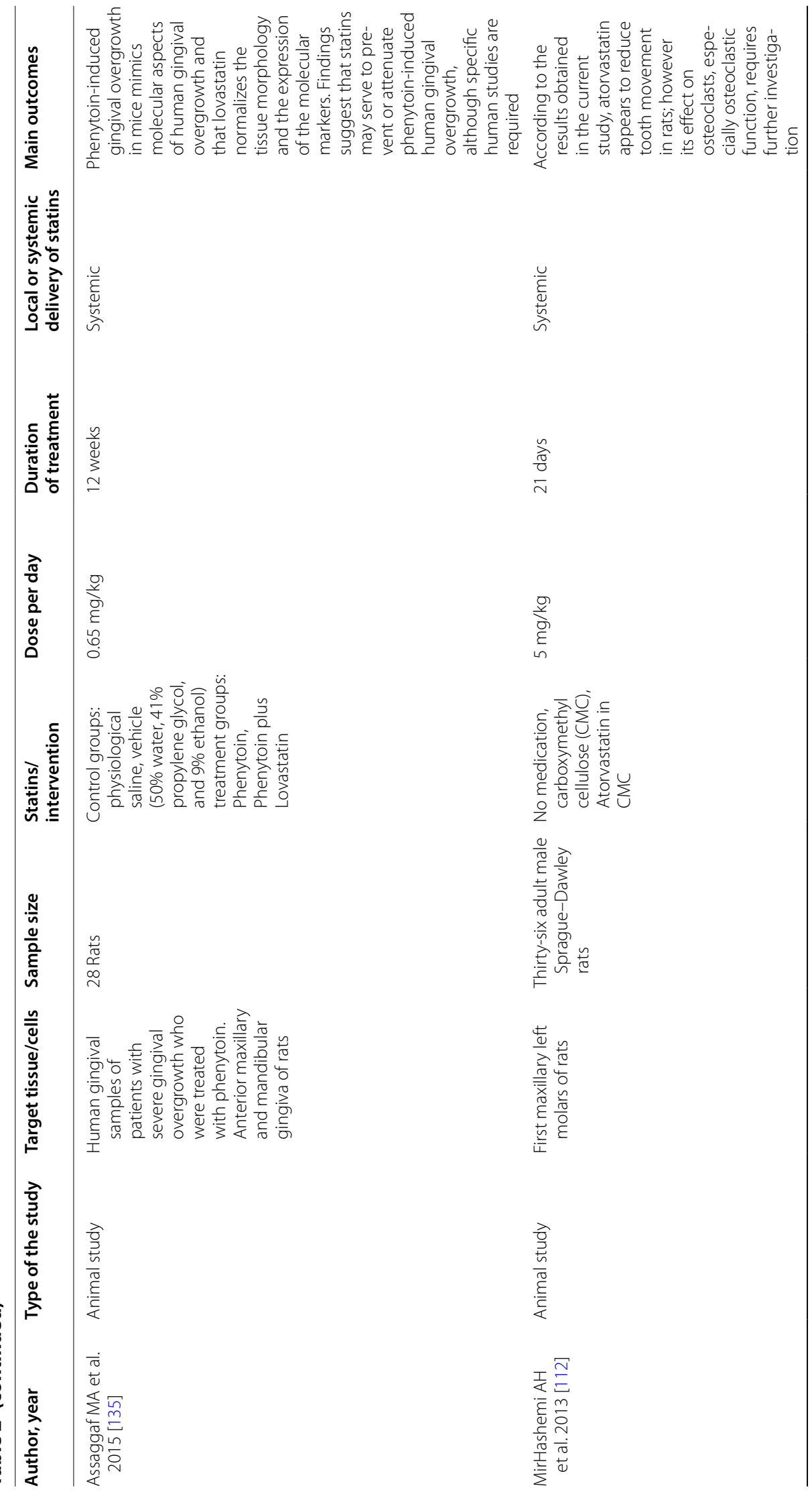




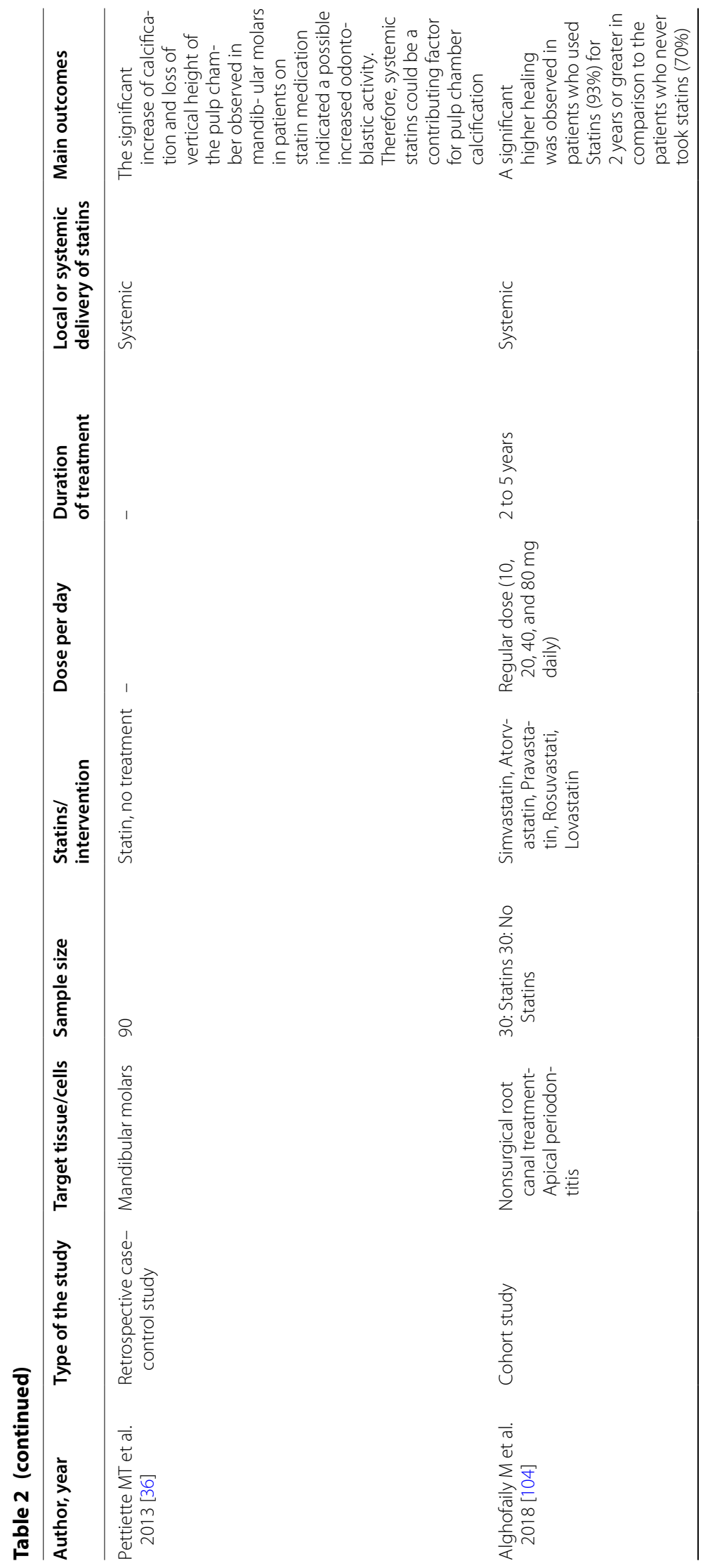




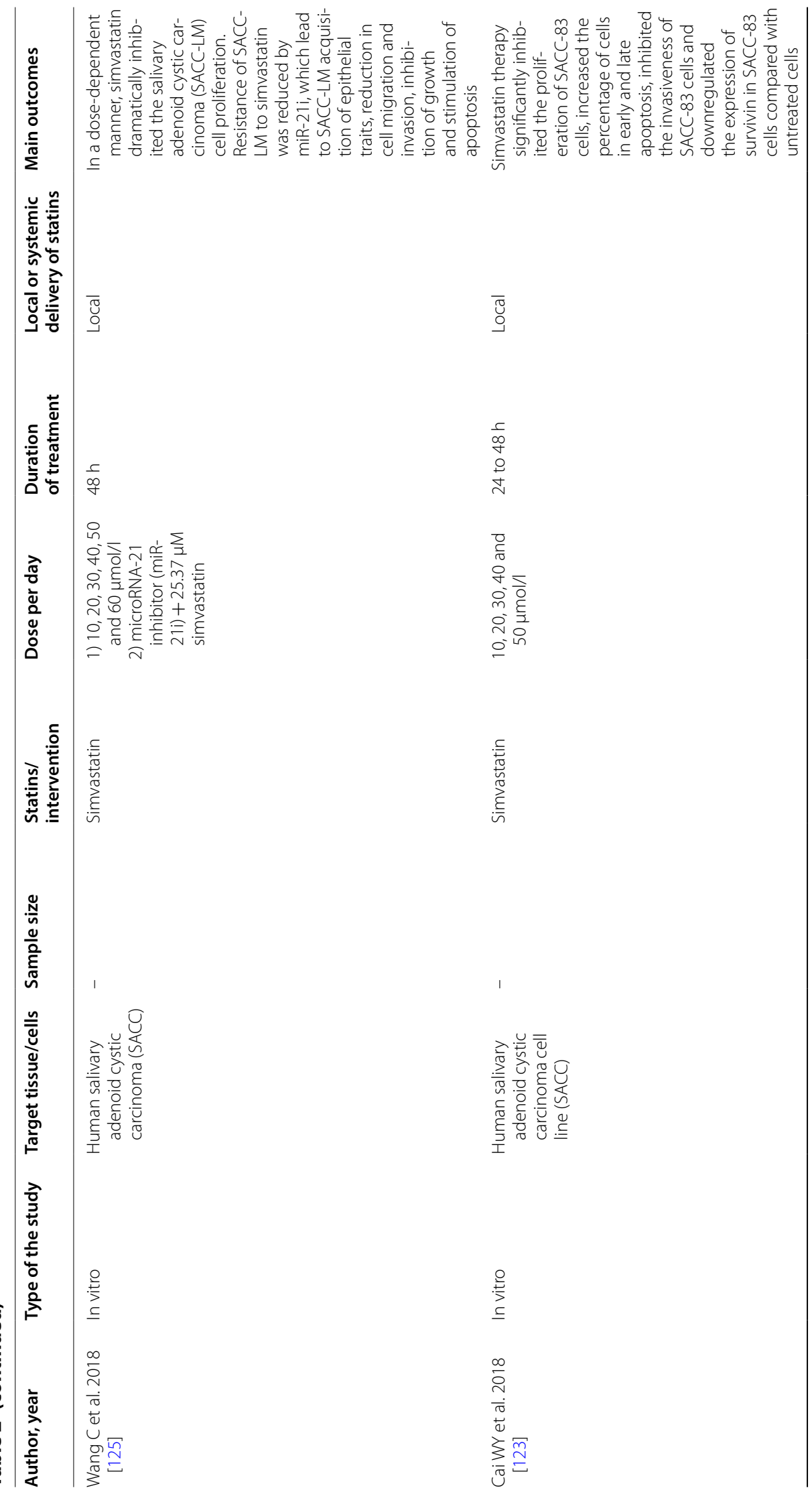




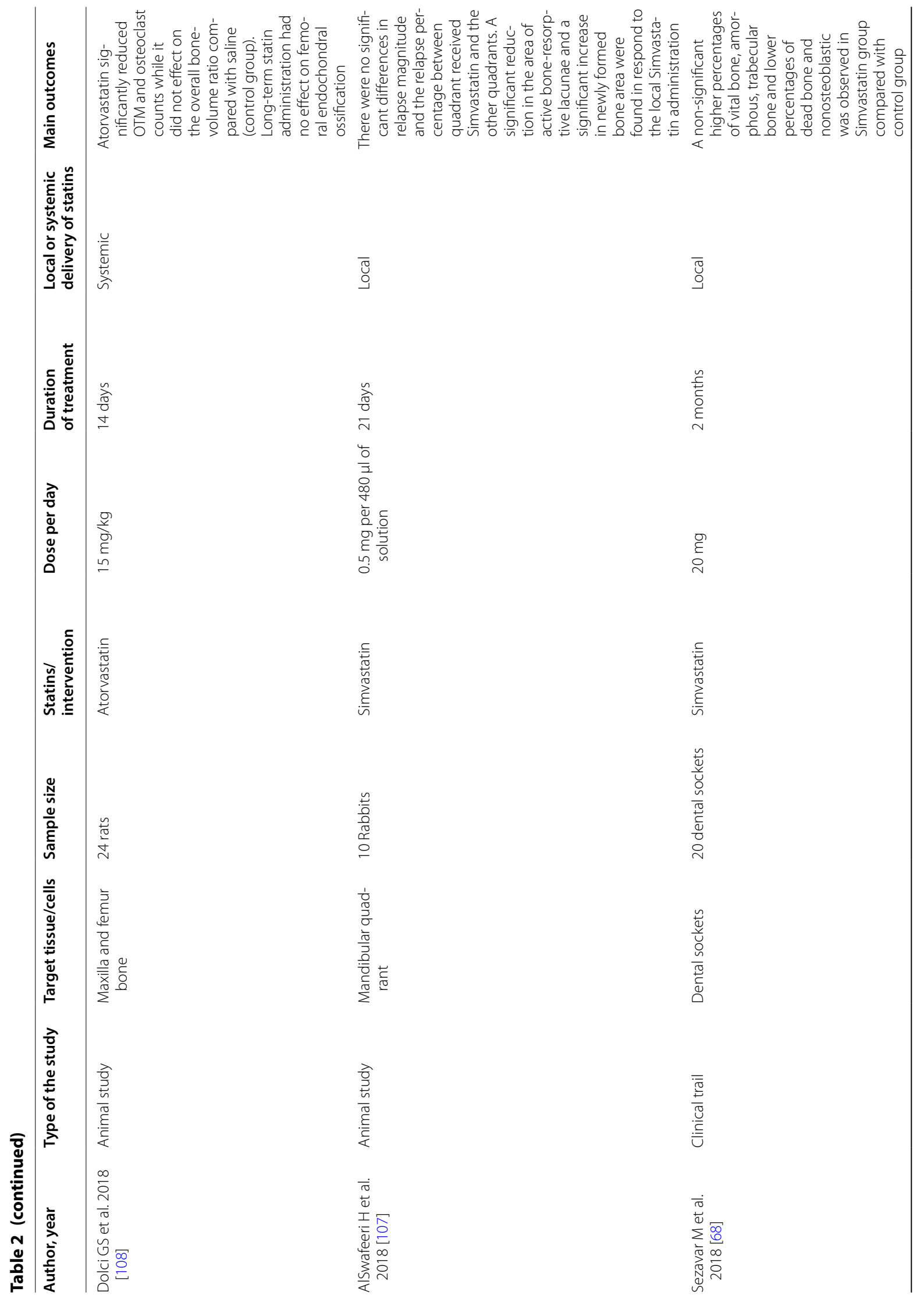




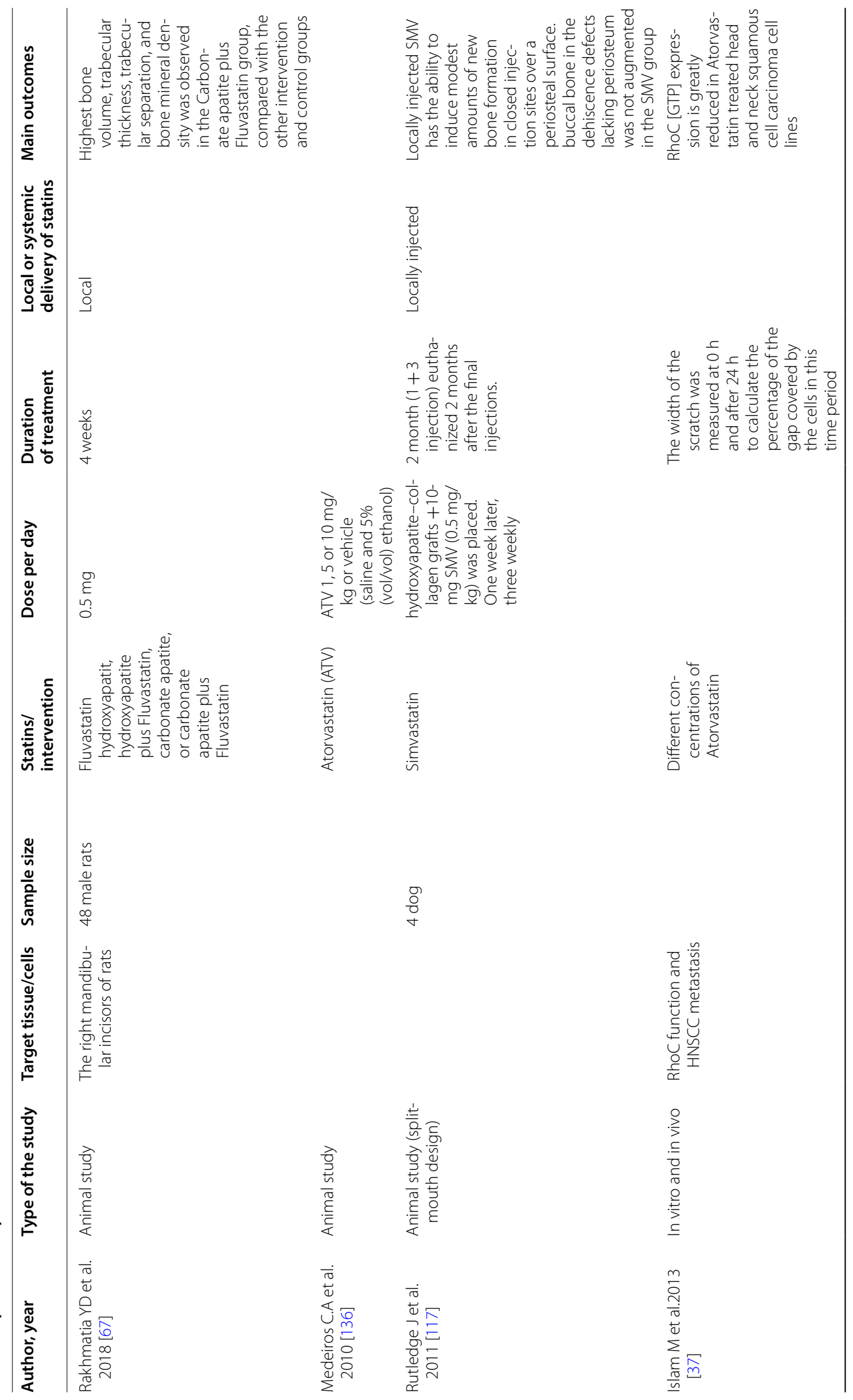




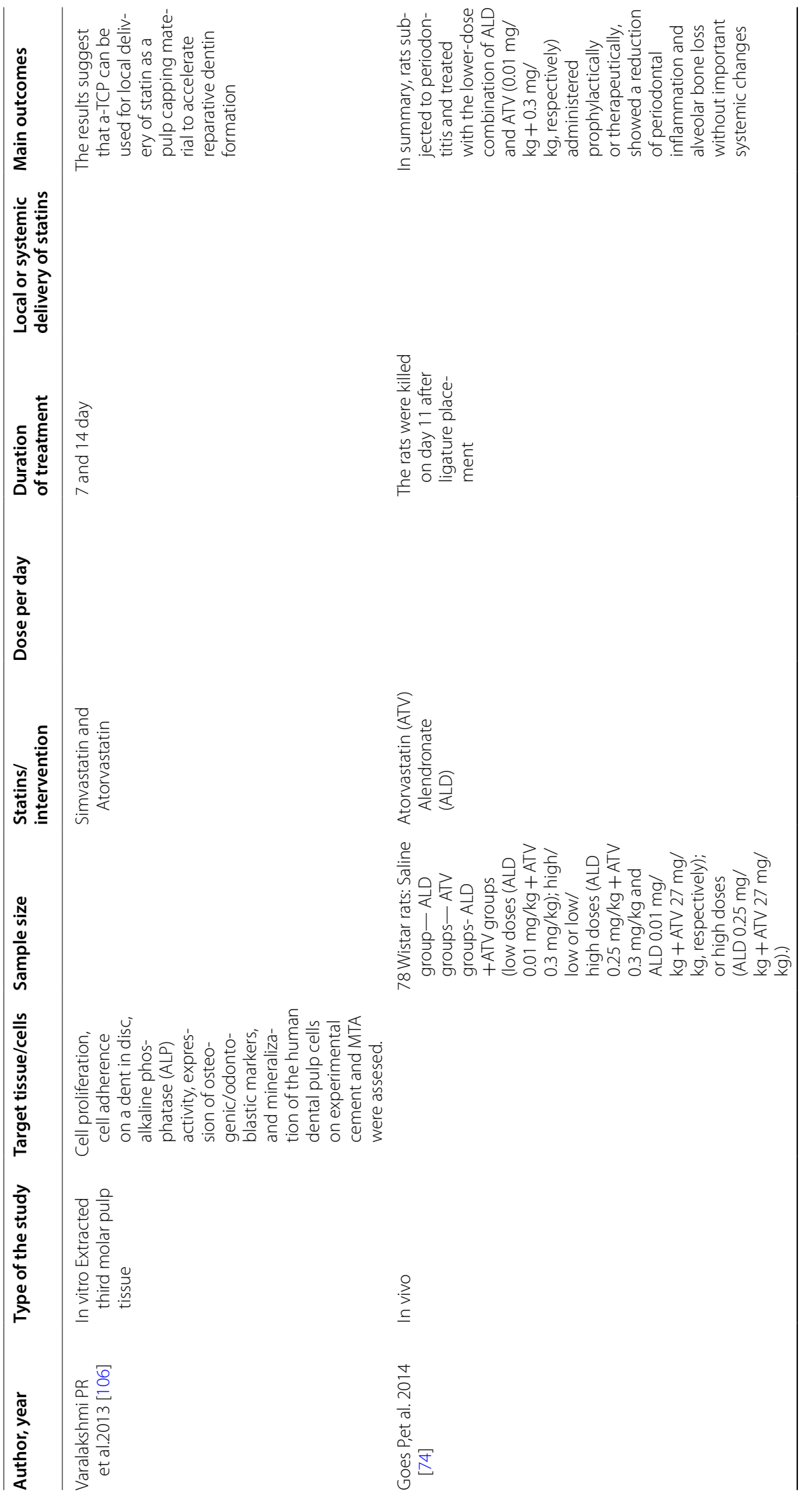




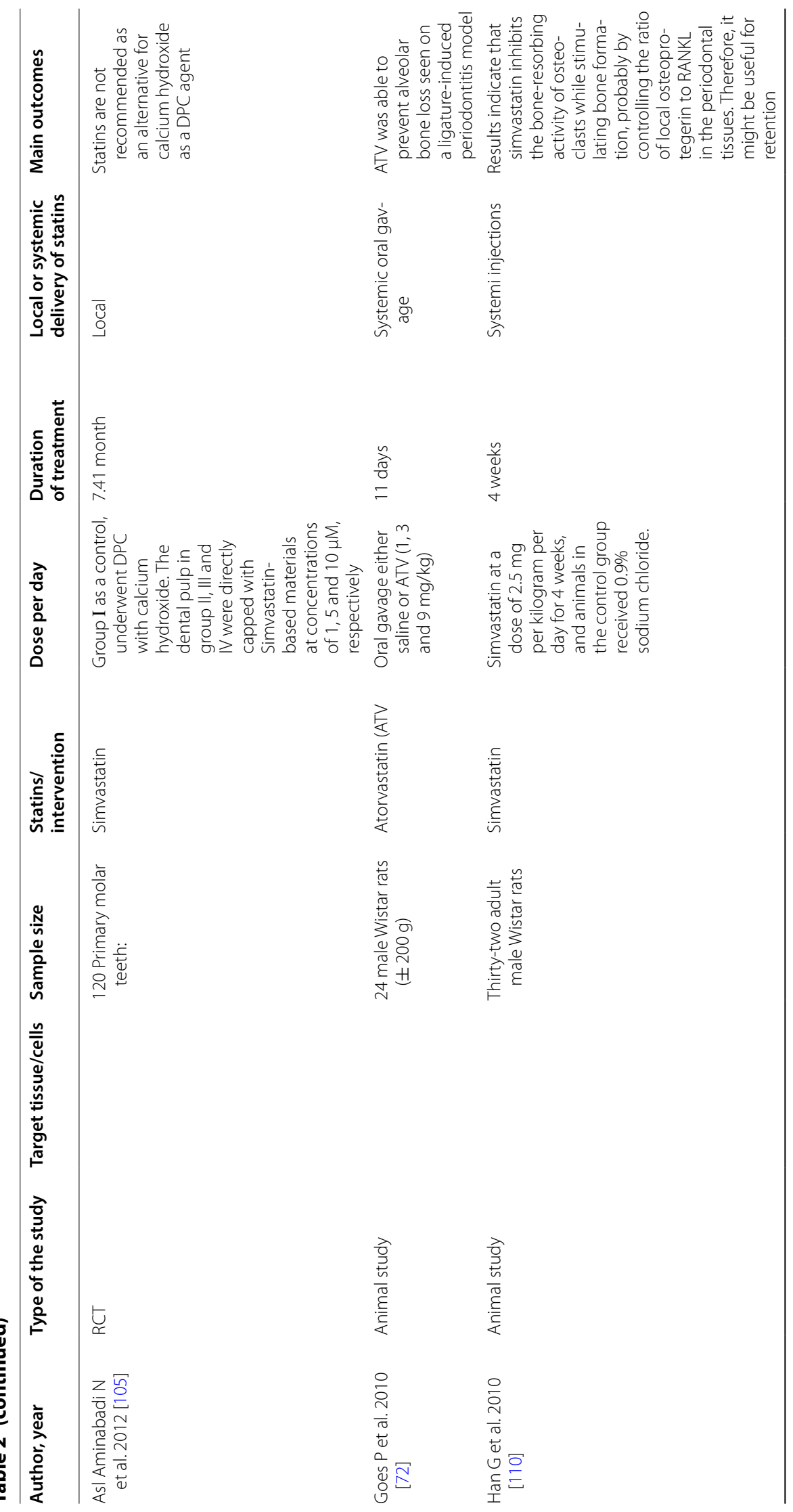




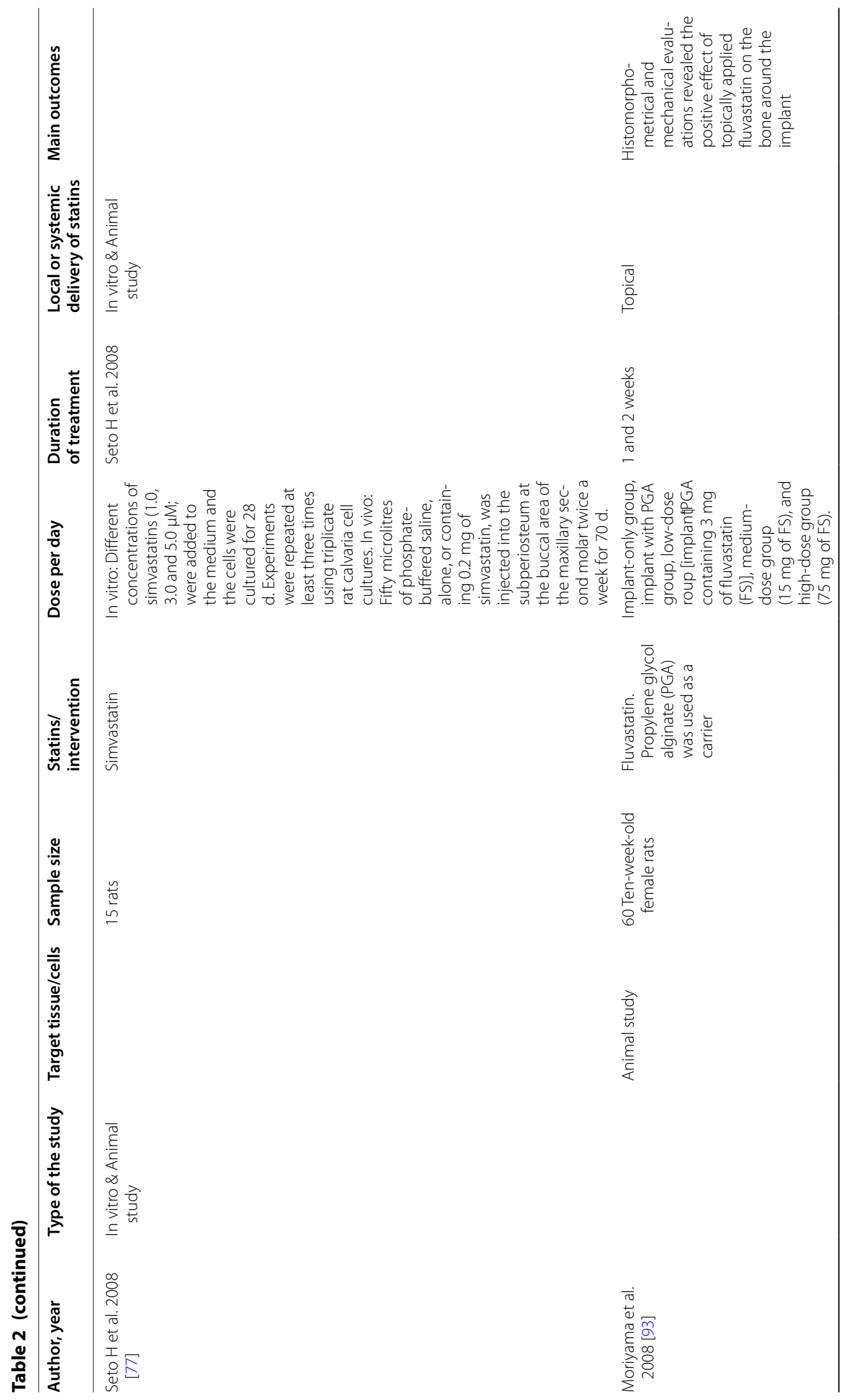




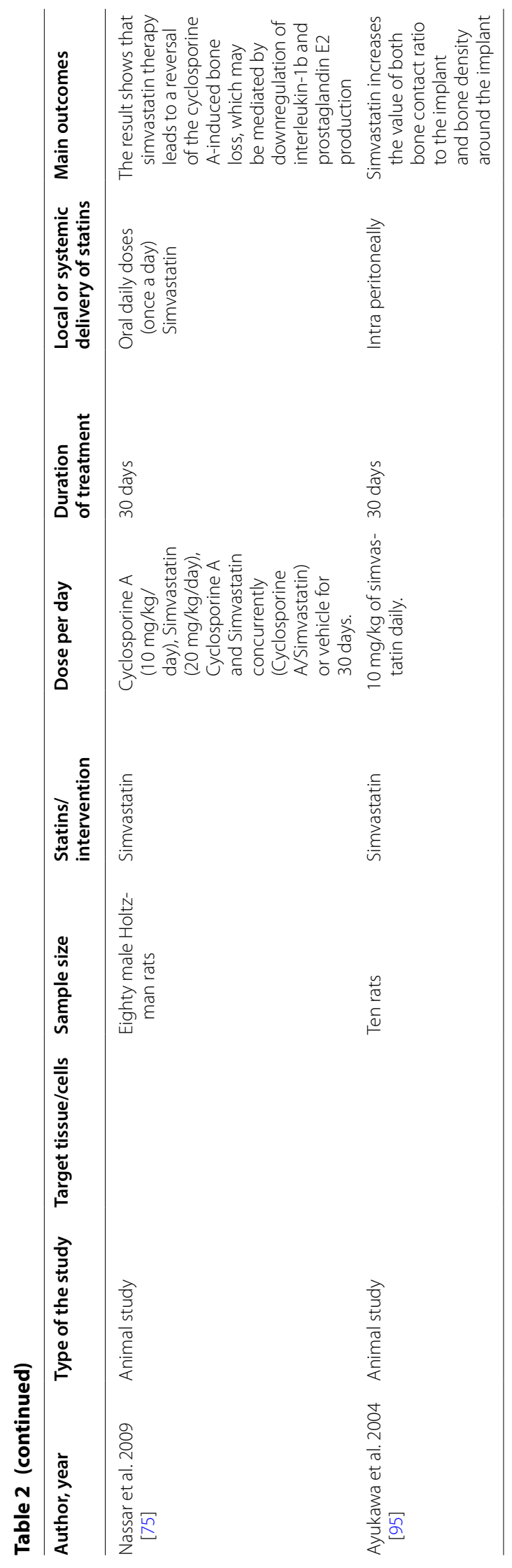


cells [51, 59-61]. Statins also enhance osteoblastic differentiation and viability $[62,63]$, increase the expression of bone morphogenetic protein, as well as vascular endothelial growth factors, and, finally, interfere with bone resorption and the process of osteoclastogenesis $[64,65]$. Due to the large variation caused by different species, defect types, evaluation methods, and reporting in these studies that utilized acute/chronified periodontal defect (ACP) models, no meta-regression was possible with these studies. Furthermore, none of the preclinical in vivo periodontitis models are able to reproduce the identical conditions to naturally-occurring periodontitis in humans. Not all available statins have been evaluated to date and, therefore, further research is needed to identify the maximum effective concentration/dose and optimal drug formulation to exploit the potential synergistic effect of statins when combined with other therapeutic agents/procedures used in treating various dental diseases.

Collectively, adjunctive use of statins appears to be effective in reducing pocket depth, clinical attachment gains, and bone defect fill in chronic periodontitis, so statins may potentially be promising therapeutic agents for periodontal regeneration.

\section{Effects of statins on alveolar bone loss due to either extraction or chronic periodontitis}

Thirteen studies investigated the effectiveness of statins on alveolar bone. Five studies evaluated alveolar bone loss following tooth extractions [66-70], while other studies were designed to investigate inflammatory periodontitis-mediated alveolar bone loss [71-78].

\section{The effect of statins on alveolar socket preservation following extractions: animal studies}

Three animal studies investigated the effect of statins on alveolar bone resorption following tooth extractions. In two studies, a statin was applied locally with poly-lacticco-glycolic acid (PLGA) [69, 70], while in the third study, it was delivered with hydroxyapatite (HA) or carbonate apatite (CO) [67].

Studies in which a statin was incorporated into PLGA and subsequently applied into the socket following tooth extraction have reported significantly larger alveolar ridge height and apparent bone deposition line after 12 weeks when compared to the same clinical parameter in the control group. [69, 70].

In the third study, Micro-computed tomography (micro-CT) and histological analyses revealed the greatest bone mineral density and the highest bone volume, trabecular thickness, and trabecular separation in the carbonate apatite $(\mathrm{CO})+$ statin group compared to the other groups (CO, HA, and HA+statin). [67]. These three animal studies showed that statins reduced alveolar bone resorption following tooth extractions.

\section{The effect of statins on alveolar socket preservation following extractions: randomized clinical studies}

Two randomized clinical trials were designed to investigate the effectiveness of statins to prevent alveolar bone resorption that can arise following a tooth extraction.

One of these trials reported a higher percentage of vital, amorphous and trabecular bone in the simvastatin group after 2 months, though it should be noted that the differences were not statistically significant [68].

In the second trial, the healing of third molar postextraction sockets were evaluated clinically and radiographically after utilizing different ridge preservation techniques. Cone beam computed tomography (CBCT) evaluations revealed that PLGA/HA/statin and PLGA/ HA groups failed to form bone after 3 months, although the biomaterial with simvastatin proved to be superior to the scaffold (biomaterial) without simvastatin and the former group had less clinical complications than the latter group [66].

These two studies failed to show beneficial effects of statins on alveolar socket preservation. Further randomized clinical trials are needed to evaluate the effect of Statins on socket preservation considering the limitations of these two trials.

Tooth extraction is an acute and brief periodontal trauma but with progressive alveolar bone resorption during the first weeks following the extraction. As the alveolar bone is easily accessible during the extraction procedure, local application of statins in the sockets would seem to represent an ideal adjunctive strategy to limit resorption of the alveolar ridge [79]. In three animal studies, the local administration of statins demonstrated a significant reduction in the resorption of alveolar bone following tooth extraction. Direct local administration of a statin has been investigated and shown to result in enhanced periodontal bioavailability of the statin due to avoidance of the hepatic first-pass effect. Of note, a onetime local administration can be achieved using a suitable carrier (e.g., a PLGA or gelatin hydrogel) to provide slow and controlled release of the statin. The in vitro release kinetics of simvastatin from either a simvastatin-PLGA scaffold, or other simvastatin-hydrogel formulations, such as those employing gelatin, has been demonstrated to be gradual and constant (zero-order kinetic) [69, 70, 78]. 


\section{Effect of statins on inflammatory alveolar bone loss caused by periodontitis: animal studies}

Six animal studies in rodents using different periodontitis models investigated the effectiveness of statins on inflammatory bone loss. Both systemic and local administration of statins was evaluated.

In one of these studies, the effect of fluvastatin on $P$. gingivalis lipopolysaccharide (LPS)-induced alveolar bone loss was examined in rats. It was shown that the administration of fluvastatin in mice reduced alveolar bone erosion and P. gingivalis LPS-induced osteoclastogenesis [76].

In a different animal study, the anti-resorptive effects of atorvastatin (ATV) on experimental alveolar bone loss $(\mathrm{ABL})$ was evaluated in Wistar rats. In this study, the administration of ATV at a dose of $27 \mathrm{mg} / \mathrm{kg}$ prevented $\mathrm{ABL}$, cemental resorption, and infiltration of inflammatory cells induced by the ligature. [73].

In another animal study, it was reported that administration of a lower dose combination of alendronate (ALD) and ATV $(0.01 \mathrm{mg} / \mathrm{kg}+0.3 \mathrm{mg} / \mathrm{kg}$, respectively) reduced periodontal inflammation, $\mathrm{ABL}$ and secretion of matrix metalloproteinases (MMP-1, MMP-2, MMP3 , and MMP-9) in ligature-induced periodontitis in rats [74].

The effect of simvastatin on bone metabolism was also evaluated in an animal study. These investigators evaluated the effects of simvastatin on ligature-induced periodontitis in rats. Microcomputed tomography images revealed that simvastatin treatment reversed the ligatureinduced alveolar bone resorption and produced a $46 \%$ increase in bone height. These findings demonstrated that simvastatin had the potential to stimulate the function of osteoblasts and further suggested that topical administration of simvastatin might be an effective strategy to recover alveolar bone loss in rats [77].

An animal study was also conducted to evaluate the efficient delivery of a simvastatin solution directly to bone defects. These investigators evaluated the release of water-insoluble simvastatin using a hydrogel, which incorporated or contained statin-micelles, in a rabbit model of tooth bone defect. It was shown that the biodegradable hydrogel comprised of gelatin was able to provide the sustained release of water-insoluble simvastatin. The hydrogel appeared to augment the simvastatin-induced bone regeneration by virtue of providing biocompatible gelatin fragments and, therefore, it was suggested that the gelatin-based hydrogel may represent an effective vehicle/platform to deliver a wide range of water-insoluble drugs [78].

Finally, one article investigated the effect of simvastatin on cyclosporine A-induced ABL, which is an important negative side-effect of cyclosporine A. Overall, treatment with simvastatin as an anti-inflammatory agent improved cyclosporine A-associated ABL. In summary, this study showed that simvastatin therapy led to a reversal of cyclosporine A-induced bone loss, which is thought to be mediated by down-regulation of interleukin-1b and prostaglandin E2 production [75].

Animal studies have reported that local statin application is effective in reducing the resorption of alveolar bone in experimentally-induced periodontitis [77, 80]. Significant reductions in periodontitis-induced alveolar bone resorption has also been reported following oral statin administration [81-87]. However, it should be noted that in five animal studies, the oral dose of the statin used (simvastatin) was tenfold greater (10$30 \mathrm{mg} / \mathrm{kg} /$ day) than the dose typically used to produce cholesterol-lowering in clinical practice (up to $1 \mathrm{mg}$ / $\mathrm{kg} /$ day) [81, 83-86]. No significant reduction in bone resorption was reported with a lower oral dose of simvastatin $(3 \mathrm{mg} / \mathrm{kg} /$ day $)$, suggesting a dose-dependent effect with a minimum threshold dose [81]. In addition to oral administration of statins to reduce bone resorption, repeated transmucosal injection of a statin has been evaluated. The statin injection protocol involved transmucosal injections once or twice a week for 3 to 10 weeks. The statin was injected in the absence of any carrier. Although this manner of statin administration to prevent bone resorption was effective in preclinical studies, this type of protocol for statin administration would obviously not be well-suited for actual clinical practice. Thus, a single local application of a statin incorporated in a suitable biocompatible carrier has been investigated in five randomized clinical studies for the treatment of chronic periodontitis in addition to conventional scaling and root planing. In these trials, significant improvement in clinical and radiological parameters was reported in the experimental group of patients after 6 and 9 months of receiving the statin when compared with corresponding measurements for the control group. The concentration of simvastatin in the aforementioned clinical trials $(1.2 \mu \mathrm{g} / \mathrm{site}$ with a carrier) [88-90] was far lower than the doses used in the animal studies (total doses of $1.5 \mathrm{mg}$ and $4 \mathrm{mg}$ ) $[77,80]$. The use of a carrier for the protracted and controlled local delivery of a statin may enhance the bioavailability of the statin in periodontal tissues and, therefore, allows for a much lower dose of the statin to be utilized.

This review has provided ample evidence/support for the local delivery of statins as a means to significantly reduce alveolar bone resorption following tooth extraction, as well as during periodontitis. The incorporation of a statin into a biodegradable carrier for the prolonged and controlled release of the drug after a single 
application may represent a more convenient mode of drug delivery for clinical use, rather than repeated injections into periodontal tissues.

\section{The effect of statins on osseointegration of implants}

To the best of our knowledge and using our search criteria described above, we uncovered six studies that had been designed to evaluate the effectiveness of the statin family of drugs on osseointegration of implants [32, 91-95].

\section{Effect of statins on osseointegration of implants: animal studies}

Three recent systematic reviews, which summarized the histomorphometric outcomes of animal studies, investigated the capacity of topical and systemic statins to function as a pro-osteogenic agent to improve osseointegration of dental implants. Results of all of the selected studies indicated that statins had a statistically significant increase on the formation of bone around the implants. Statin administration increased both bone formation and density, and also enhanced new bone formation (NBF) around implants and/or bone-to-implant contact. The majority of studies reported that statin administration enhanced NBF around implants in osteoporotic rats. However, one study showed that implant surfaces coated with a Statin actually impaired osseointegration [47, 91, 92].

The effect of local application of fluvastatin on osteogenesis around titanium implants was also evaluated in two animal studies. Both studies showed that at 2 and 4 weeks, however, the bone-implant contact (BIC) and MBV were both significantly higher in the group of rats that received the 75 microg dose of fluvastatin when compared to the non-fluvastatin-treated groups $(\mathrm{p}<0.01)$. Furthermore, the data showed positive correlation between the MBV and the push-in strength. These results demonstrate that locally applied fluvastatin is beneficial to bone adjacent to titanium implants and suggests that that this finding may be partially explained by calcification of the peri-implant bone [94].

Another study examined the promotion of osteogenesis around titanium implants when rats were treated with simvastatin. Results showed that thicker bone trabeculae with a mesh-like structure was abundantly observed in the medullary canal in the experimental group. Additionally, both the BCR and BD in the experimental group of rats were significantly greater than these same parameters for rats in the control group [93].

Results from $\sim 95 \%$ of studies show that local and systemic statin administration is effective in enhancing osseointegration and the formation of new bone around implants. These results would appear to be strong enough to conclude that osseointegration is enhanced by local and systemic administration of statins. However, there are a number of reasons it would be difficult to replicate these experimental results in a clinical setting. First, a precise route of drug administration for statin in humans must be established. For example, in some studies, simvastatin was administered by intraperitoneal injections $[95,96]$, whereas, in other studies, statins were administered subcutaneously [97], orally [98], by intraosseous injection [99], or percutaneously [100]. Secondly, the dose and frequency of statin dosing varied between the studies. This reflects the fact that in a clinical situation, the route of administration, dosage, and frequency of statin dosing was not consistent in the studies included in this review, and this needs to be further clarified. It is notable that the there was a maximum 12-week follow-up period in the experimental studies [93-101]. It remains unclear whether systemic or local administration of statins in patients receiving dental implants would increase BIC and contribute to the success and survival of dental implants for greater than 5 years.

Furthermore, it should also be mentioned that the statin doses used in the animal models were approximately tenfold greater than the daily human dose of a statin. Moreover, the route of drug administration was often percutaneous instead of by the oral route of drug administration used in humans. Further complicating factors include the fact that the tibia bone in rats is structurally different from human alveolar bone, the microbial flora in the human oral cavity is more complex than that of rat tibia, and no occlusal forces around the human implants can be reproduced in the rat tibia model. Finally, when compared to locally-delivered statins in the implant osteotomy site, the first-pass effect for orally administered statins renders approximately $10-20 \%$ of the drug available to the general circulation and, thus, might not exert a significant effect on bone remodeling around the dental implants.

Studies have shown that systemic diseases such as osteoporosis jeopardize osseointegration, which leads to a reduction in implant stability [102]. However, it is well-established that statins have a beneficial effect in the treatment of osteoporosis, which has been confirmed in vivo and in clinical practice [31, 103]. However, controversial results exist, which are associated with different factors such as type of statin, route of administration, and dosage.

To sum up, local and systemic statin delivery seems to enhance osseointegration. However, further randomized clinical trials are needed to assess the role of statins in improving osseointegration around dental implants. 


\section{The effect of statins on dental pulp cells}

Seven studies evaluated the efficacy of statins on dental pulp cells [34-36, 53, 104-106]. Six studies were conducted in humans.

\section{Clinical studies}

In a cohort study, 30 patients using statins during either nonsurgical root canal treatment, or retreatment, and 30 patients who did not take statins were included and followed for 2 to 5 years after treatment. At the completion of the study, a significantly higher healing of preoperative apical periodontitis (periapical index was used to determine healing) was observed in the patients who used statins for 2 years or more in comparison to the patients in the control group [104].

Uncovered in our review of the literature was also a retrospective case-controlled study that investigated the role of systemic administration of statins on odontoblastic differentiation of dental pulp stem cells. Digital bitewing radiographs of mandibular molars showed a significant reduction in the height ratio of the pulp chamber in the statin group when compared with the control group. The significant increase in calcification and the loss of vertical height of the pulp chamber observed in mandibular molars in patients taking statin medication would appear to suggest increased odontoblastic activity. Therefore, systemic statins may be a contributing factor for calcification of pulp chambers [36].

The combined effect of statin and alpha-tricalcium phosphate (alpha-TCP) on odontoblastic differentiation of human dental pulp cells (HDPCs) and its comparison with mineral trioxide aggregate (MTA) were investigated in one study. TCP-simvastatin and TCP-atorvastatin promoted odontogenic differentiation in HDPCs as documented by the expression and activity of osteogenic/ odontogenic markers (i.e., DSPP, DMP 1, ALP, BMP-2, and $\mathrm{OCN}$ ), as well as the formation of mineralized nodules, which was comparable with the MTA group. The results suggested that alpha-TCP may be used for the local delivery of simvastatin as a pulp capping material to hasten the formation of reparative dentin. Moreover, as mentioned previously in this review, statins have been shown to exert anti-inflammatory effects, so this beneficial property may also help to restore inflamed pulp tissue [106].

In a different study, a randomized clinical trial evaluated the efficacy of simvastatin at concentrations of 1 , 5 , and $10 \mu \mathrm{M}$ and compared to calcium hydroxide with regard to direct pulp capping of human primary molars. The results indicated that hard tissue formation and healing without inflammation occurred following the statin treatment, but at a lower rate than the calcium hydroxide [105].
Another study assessed the effect of simvastatin on tumor necrosis factor alpha (TNF-alpha)-induced synthesis of Cyr61 and $\mathrm{C}-\mathrm{C}$ motif chemokine ligand-2 (CCL2) in MG-63 human osteoblasts. Cysteine-rich 61 (Cyr61) and CCL2 are potential osteolytic mediators in inflammatory bone diseases. A Western blot analysis showed that TNF-alpha stimulated Cyr61 synthesis in MG-63 cells. However, the addition of simvastatin attenuated this effect in a dose-dependent fashion. Simvastatin also reduced the levels of TNF-alpha-induced CCL2, although the inhibitory effects were restored by exogenous Cyr61. The administration of simvastatin markedly diminished the severity of experimentally-induced rat periapical lesions as determined using radiography and histopathology. There was also a decrease in the numbers of Cyr61-synthesizing osteoblasts and CD-68-positive macrophages. It has been suggested that simvastatin limits the progression of apical periodontitis, possibly by diminishing Cyr61 expression in osteoblasts and, subsequently, by reducing macrophage chemotaxis into the lesions [53].

One study was designed to evaluate the application of poly (D, L-lactide-co-glycolide acid) (PLGA) nanoparticles that contained lovastatin in direct pulp capping. The results showed less toxicity to cultured human dental pulp cells with the PLGA-lovastatin nanoparticles than free lovastatin after 5, 9, and 13 days. Additionally, PLGA-lovastatin nanoparticles induced the greatest expression of mRNA and dentin sialophosphoprotein (DSPP), dentin matrix acidic phosphoprotein 1 (DMP1), and osteocalcin $(\mathrm{OCN})$ in the cultured pulp cells.

\section{Animal studies}

One study was designed to compare PLGA-lovastatin nanoparticles and mineral trioxide aggregate (MTA) as direct pulp capping materials for teeth using Wistar rats. Upon histological evaluation, it was revealed that MTA was superior to PLGA-lovastatin nanoparticles in terms of stimulating the formation of tubular dentin after 2 weeks. However, following an observation period of 4 weeks, it was evident that PLGA-lovastatin nanoparticles and MTA were very similar in mediating the formation of tubular reparative dentin and a complete dentinal bridge [35].

An animal study investigated the effect of different concentrations of simvastatin on the proliferation and differentiation of dental pulp stem cells (DPSCs) and pulp regeneration after pulpotomy. The results showed that simvastatin $(1 \mathrm{mmol} / \mathrm{L})$ suppressed the proliferation of canine dental pulp stem cells (cDPSCs), but the activity of alkaline phosphatase and mineral nodule formation were both significantly increased. In addition, the areas of pulp and dentin regeneration in the simvastatin group 
were significantly higher than these same parameters in the other groups [34].

Collectively, the results of these various studies indicate that introduction of statin-treated DPSCs into the pulp chamber can lead to coronal pulp regeneration, as well as dentin restoration. Therefore, it was concluded that statins stimulate both the mineralization of DPSCs and the formation of dentin in vivo and in vitro. It should be emphasized that statin-treated DPSCs showed an increase in the activity of ALPase and mineral nodule formation.

Statins have been investigated as a novel, alternative agent for pulp capping. Because statins exert antiinflammatory properties as one of their many pleiotropic effects, they are of interest to practicing dentists and specialists alike. Pulp and periapical symptoms can be modulated with the use of statins, and they can also potentially decrease the development of apical periodontitis.

\section{Statins and orthodontic tooth movement/orthodontic relapse}

A potential clinical concern during orthodontic treatment is that statin therapy may be associated with the promotion of osteogenesis and the suppression of bone resorption. Seven studies included in this review were designed to investigate the effect of statins on orthodontic tooth movement and relapse [107-113]. Only one of these studies was conducted on humans [111].

\section{Effect of statins on orthodontic tooth movement/orthodontic relapse: animal studies}

The effect of atorvastatin on orthodontic tooth movement (OTM) and the potential adverse effects of atorvastatin on long-bone turnover and endochondral ossification were examined in an animal study. Results indicated that atorvastatin significantly reduced OTM and osteoclast counts, while it did not affect the overall bone:volume ratio. Long-term statin administration had no effect on femoral endochondral ossification [108].

Another animal study also evaluated the effect of atorvastatin on OTM in rats. Results showed that there was a statistically significant $(\mathrm{p}<0.05)$ reduction of OTM following administration of atorvastatin, but there was no significant difference $(\mathrm{p}>0.05)$ in various histologic indices [root resorption, periodontal ligament (PDL) width, and osteoclast number] among the three groups [112].

The effect of local administration of simvastatin on post-treatment relapse was evaluated on 10 rabbits [114]. At post-intervention, the magnitude of relapse, as well as the percent relapse, between the two quadrants did not demonstrate differences that were statistically significant, although, based on histomorphometric analyses, a significant reduction in the area of active bone-resorptive lacunae and a significant increase in newly-formed bone area was determined in response to local simvastatin administration [107].

Another animal study evaluated the effect of simvastatin on relapse of tooth movement in rats using microcomputed tomography (micro CT), and also determined whether there was a positive correlation between bone density and orthodontic relapse. Relapse and bone mineral density (BMD) were lower in the experimental group, but did not reach statistical significance. Additionally, these investigators found no correlation between bone density and orthodontic relapse [113].

The effects of simvastatin on orthodontic relapse and the remodeling of periodontal tissue following experimental tooth movement in rats was evaluated in a different animal study. Osteoprotegerin was strongly expressed on both sides of the PDL in the simvastatin group when compared to the control group. All results demonstrated that simvastatin effectively stimulated bone formation. This suggests that simvastatin has the potential to accelerate tooth stability in a new position, assist retention of teeth, and stabilize any loosened teeth in patients with periodontal disease. Furthermore, RANKL was strongly expressed, and its expression on both sides of the PDL was higher in the control group than in the simvastatin group [110].

The effect of Atorvastatin (ATV) on orthodontic relapse and osteoclastogenesis was investigated in one animal study by evaluating the expression of RANKL and osteoprotegerin (OPG). The results showed that ATV decreased tooth relapse and osteoclast counts which were positively correlated. Moreover, there was an increase in periodontal expression of OPG, but not RANKL with statin administration [109].

\section{The effect of Statins on orthodontic tooth movement/ orthodontic relapse: clinical trial}

The effect of simvastatin on space re-opening after orthodontic space closure and its impact on the gingival index (GI) and clinical attachment loss (CAL) were evaluated in a randomized clinical trial. Those patients that had received the simvastatin gel had a significant reduction in space re-opening $(\mathrm{p}<0.001)$. Moreover, GI reduction was significantly greater $(\mathrm{p}<0.001)$ in the simvastatin group when compared to the control group. However, there was no significant difference between the experimental and control groups with regard to CAL [111].

In general, it has been shown in numerous studies that statins reduce orthodontic relapse. Findings in the above studies suggest that daily administration of statins affects bone resorption during orthodontic relapse, which was demonstrated by a significant decrease in the overall osteoclast count. Taken together, these results 
demonstrate that statins mediate the inhibition of osteoclastogenesis and may represent a potential target with which to minimize orthodontic relapse.

In addition, there have been some studies that have reported that simvastatin (SMV) promotes bone formation, as well as inhibits osteoclast activity [65, 115]. Statins can stimulate regeneration of new bone in rodents, and this effect appears to be related to increased expression of bone morphogenic protein- 2 in osteogenic cells. Simvastatin at low concentrations exhibits a positive effect on the reproduction and differentiation of PDL cells to osteoblasts. SMV also limits osteoclast activity, while stimulating the formation of bone. The effects of SMV on osteoclast activity and bone formation would seem to suggest that its action is exerted by regulating the ratio of local osteoprotegerin to RANKL in periodontal tissue. Therefore, it has been suggested that SMV might be useful for tooth retention [110].

As mentioned above, the use of statins to inhibit osteoclastogenesis may represent a viable therapeutic strategy with which to minimize orthodontic relapse.

\section{Statins and tissue healing (wound/bone healing)}

Three studies evaluated the efficacy of statins on wound and bone healing [116-118].

\section{The effect of Statins on tissue healing: animal studies}

One study using rats investigated the effect of local administration of rosuvastatin (RSV) on mandibular fracture healing. Animals in groups with the number 14 or 28 were euthanized 14 days, or 28 days, after the operation, respectively. Stereologic analysis showed that the rats contained in group R-14 had significantly more new bone at 2 weeks compared with those rats in group $\mathrm{C}-14$. The volume of connective tissue was also significantly greater in rats included in group R-14, although there was no significant difference in this parameter between groups C-28 and R-28. These authors concluded that locallyadministered RSV enhances early bone regeneration after mandibular fracture in rats [118].

The effectiveness of simvastatin injections in an ethanol carrier was evaluated in an animal study (beagle dogs) using several human-like clinical situations (dehiscence defect on root, thin bone on root, and ridge augmentation). Application of simvastatin to alveolar bone surfaces is a clinically safe procedure with few adverse effects other than a moderate degree of swelling at the site of injection. However, the use of simvastatin did not enhance the bone width gain obtained with buccal overbuilding procedures performed with the hydroxyapatite graft and membrane in this model. Specifically, multiple injections of simvastatin did not enhance new bone deposition over dehiscence bone defects where no periosteum exists [117]. Although repeated injections of simvastatin induced new bone deposition over thin alveolar bone covering root surfaces and in edentulous sites, nevertheless, it would seem that additional prospective studies are warranted to unequivocally identify the best animal model to evaluate the effects of repeated simvastatin injections in order to prevent the loss of thin alveolar bone (dehiscence defects, recession, and post extraction bone loss).

\section{The effect of statins on tissue healing: clinical studies}

In one study, the effect of intra-oral topical application of simvastatin/chitosan gel $(10 \mathrm{mg} / \mathrm{mL})$ over the palatal donor site following a free gingival graft (FGG) procedure was evaluated. Statistically significant reductions in wound-healing scores were observed after 3 and 7 days for (simvastatin/chitosan gel) group when compared to other groups. A significant reduction was also observed in the visual analog scale (VAS) score on days 1, 3, 5 and 7 when compared to the other groups on the same days [116].

Statins can also accelerate epithelization and the rate of wound closure by inhibiting adhesion and extravasation of leukocytes into the site of inflammation, which can result in reduced co-stimulation of T-cells and a reduction in inflammatory cytokines. These processes both facilitate wound healing during the early stages of wound repair. Additionally, statins have been shown to enhance the infiltration of macrophages, which, in turn, stimulates the proliferation of fibroblasts, keratinocytes, and endothelial cells [119]. Stimulation of angiogenesis, which promotes infiltration of macrophages, as well as induces both the production of vascular endothelial growth factor (VEGF) and re-epithelialization, have also been reported following statin use [119-121].

In summary, studies would appear to support the premise that topical application of simvastatin is safe at a low concentration $(10 \mathrm{mg} / \mathrm{mL})$ and promotes wound healing. Together with their antibacterial activity and capacity to modulate the inflammatory process, this wound care strategy involving statins could potentially minimize the risk of bacterial infection during the wound healing process.

It can be concluded that topical application of statins represents a safe and promising treatment modality for promoting wound healing, however, additional clinical trials are needed to confirm these results.

\section{Statins and salivary gland function}

The radioprotective potential of simvastatin (SMV) has been investigated in a murine model of radiation-induced salivary gland dysfunction in mice. The systemic administration of SMV by intraperitoneal(i.p). injection lessened 
the reduction in saliva secretion and restored the activity of salivary amylase [122].

Results demonstrated the potential of SMV to function as a radio-protective agent for salivary glands. The protective benefits of SMV were thought to be due to scavenging of radiation-induced free radicals, minimizing collagen deposition, and reducing/delaying the elevation of transforming growth factor $\beta 1$ expression, which is induced by radiation. Therefore, it is suggested that statins may potentially represent a clinically useful treatment to alleviate the side effects of radiotherapy on salivary glands.

\section{Anti-tumor and anti-cancer effects of statins}

Four studies have evaluated the anti-cancer effects of statins in the head and neck area [37, 123-125].

One study assessed the effect of simvastatin in combination with microRNA-21 inhibitor (miR-21i) in lung metastatic salivary adenoid cystic carcinoma (SACC-LM) cells. It should be noted that one of the most prevalent malignancies of the salivary glands is salivary adenoid cystic carcinoma (SACC). Additionally, it should be emphasized that microRNA-21 (miR-21) has a substantial effect on tumor development. Results indicated that simvastatin dramatically inhibited SACC-LM cell proliferation in a dose-dependent fashion. In addition, resistance of SACC-LM cells to simvastatin was reduced by the miR-21i, which led to an acquisition of epithelial traits, a reduction in cell migration and invasion, an inhibition of growth and, lastly, stimulation of apoptosis, in the SACCLM cells [125].

In another recent study, the effect of simvastatin on the proliferation, invasion, and apoptosis of human SACC was investigated. Results demonstrated that exposure of SACC cells to simvastatin (10 to $50 \mu \mathrm{M}$ ) for 24 to $48 \mathrm{~h}$ considerably, and in a dose- and time-dependent manner, inhibited the proliferation of the SACC cells when compared to non-simvastatin treated cells. Furthermore, in response to the simvastatin, the percentage of cells in the 'early' and 'late' stages of apoptosis was increased. Finally, the invasiveness of SACC cells when exposed to simvastatin was inhibited in a dose-dependent manner, and simvastatin exposure also mediated a down-regulation in the expression of survivin (survivin is overexpressed in some types of cancers) [123].

The anti-tumor effects of statins on head and neck squamous cell carcinoma (HNSCC) were evaluated in a systematic review. Only fourteen in vitro studies that discussed the effect of statins on HNSCC were included in this review. These studies demonstrated that statins had a significant effect on HNSCC cell lines by influencing cell viability, the cell cycle, cell death, and protein expression levels that are involved in pathways associated with carcinogenesis [124].

In vitro and in vivo studies were conducted to evaluate the ability of atorvastatin to inhibit RhoC function and HNSCC metastasis. The results showed that treatment of HNSCC cell lines with atorvastatin decreased cell invasion and migration. Statin treatment also decreased the membrane fraction of Ras homolog gene family member $\mathrm{C}$ (RhoC) and limited the activation of two critical signaling pathways; namely, the extracellular signal-regulated kinase $1 / 2$ (ERK1/2) and the signal transducer and activator of transcription 3 (STAT3) signaling cascades. Most importantly, in an in vivo animal model, the inhibition of $\mathrm{RhoC}$ resulted in a decrease in metastases when compared to placebo-treated animals. In summary, this work serves to confirm the use of statins as an adjunct treatment modality to standard therapies currently available for HNSCC [37].

Currently, new therapies are emerging for oral cancer. Advanced tumors in the recurrent stage, as well as distant metastases, are currently treated with combination therapy involving surgical resection, which is followed by radiotherapy and, more often than not, chemotherapy. Almost all cancer treatments that involve radiation or pharmacotherapy are cytotoxic and cause many adverse effects for the patient. Therefore, therapeutic approaches that are less cytotoxic are desperately needed, especially for the treatment of HNSCC [126].

It has been previously recognized that statins have anticancer effects. Some results have shown that statin monotherapy can kill more than $50 \%$ of a tumor cell burden, as well as inhibit their proliferation in a dose-dependent manner. The effect of statins, when combined with either radiation, or other chemotherapeutic agents (cisplatin, 5-fluorouracil, paclitaxel, carboplatin, and oxaplatin), on HNSCC cell viability has also been investigated. However, disappointingly, the inclusion of statins with the chemotherapeutic agents mentioned directly above had no significant effect on HNSCC cell kill $[127,128]$. However, when a combination of gefitinib and lovastatin was tested using squamous cell carcinoma 9 (SCC9) cells, cell death was increased by more than $90 \%$ when compared to monotherapy with either drug $[38,129]$. Similar results were reported by Dayekh et al. when they used lovastatin combined with monensin (a polyether antibiotic isolated from Streptomyces cinnamonensis) and erlotinib [130]. Using FaDu cells in in vitro clonogenic assays, de Llobet et al. showed that simvastatin enhanced the effects of radiation treatment alone and when in combination with cetuximab in terms of cell proliferation. These authors subsequently observed that the in vitro results were reflected in xenoimplanted tumors growing into 
subcutaneous tissue of athymic mice in which concomitant treatment with simvastatin decreased tumor growth, induced apoptosis, and increased wound healing [131].

The final products of the mevalonate pathway, which includes de novo cholesterol and isoprenoids, have a potential effect on the viability of malignant cells [132]. Several of the products from the mevalonate pathway affect cell proliferation and are necessary for various key cellular functions including maintenance of cell membrane integrity, signaling, protein synthesis, and cell cycle progression. It is thought that interruption of these processes in malignant cells can inhibit tumor growth and metastasis [133]. Simvastatin has been shown to regulate the expression of phosphorylated forms of ERK $1 \backslash 2$ (extracellular-signal-regulated kinases) and the expression of cell cycle regulators, such as p21 and p27, in HNSCC cells [132, 134]. Additionally, atorvastatin treatment in vitro significantly decreases the active form of RhoC in HNSCC cells. Importantly, atorvastatin also mediates a significant reduction in the phosphorylated forms of ERK1/2 and STAT3, and reduces HNSCC cell motility, invasion, proliferation, and colony formation. These in vitro results provide support for the suggestion that statin exposure/administration may potentially represent a therapeutic intervention for the treatment of HNSCC [124].

Collectively, statins have significant anti-tumor effects on tumor cell lines with respect to the cell cycle, cell death, and through the regulation of protein expression involved in various carcinogenic pathways.

\section{The effect of statins on gingival tissue The effect of statins on gingival tissue: animal studies}

Gingival overgrowth has been shown to be caused by the anti-seizure medication phenytoin, calcium channel blockers, and cyclosporin. In one particular study, the efficacy of lovastatin to prevent phenytoin-induced gingival overgrowth was evaluated in mice. Lovastatin was selected based on previous analysis of tissue-specific regulation of $\mathrm{CCN} 2$ production in human gingival fibroblasts and because CCN2 is known to promote fibrosis and epithelial-to-mesenchymal cell transition. Lovastatin not only decreased epithelial gingival tissue growth in phenytoin-treated mice, but also altered the expression of biomarkers that indicate epithelial-to-mesenchymal cell transition. Data indicated that gingival overgrowth induced by phenytoin in mice replicates various molecular aspects of gingival overgrowth in humans. Moreover, these same authors showed that lovastatin normalized tissue morphology, a well as the expression of molecular markers evaluated in this study. Findings suggested that statins may prevent or attenuate phenytoin-induced human gingival overgrowth, although specific human studies are required to confirm this finding [135].

Cancer patients treated with cancer chemotherapeutic agents often suffer from oral mucositis (OM). The effect of atorvastatin (ATV) on OM induced by the administration of 5-fluorouracil (5-FU) to hamsters was previously investigated. OM was induced in the hamsters by repetitive intraperitoneal injections of 5-FU. ATV was effective at reducing mucosal damage and inflammation, as well as decreasing the levels of cytokines, nitrite, and myeloperoxidase activity on the 5 th and 10th day of the 5-FU-induced OM. However, the highest dose of ATV $(10 \mathrm{mg} / \mathrm{kg})$ with 5 -FU treatment induced hepatotoxicity and amplified leukopenia [136].

Three types of drugs induce gingival overgrowth with fibrosis and inflammation. As mentioned above, these drugs are phenytoin, cyclosporin, and nifedipine. Although these three medications are of different drug classes, they all can cause drug-induced gingival overgrowth with manifests as enlarged gingival epithelium and connective tissues that exhibits varying degrees of fibrosis and inflammation.

Phenytoin-induced gingival overgrowth is the most fibrotic form of gingival overgrowth and is associated with increased expression of $\mathrm{CCN} 2$, but a reduced presence of inflammatory cells. It has been shown that TGF-beta 1 is highly expressed in phenytoin-induced human gingival tissue $[137,138]$. Results in mice have demonstrated that higher expression of TGF-beta 1 in the phenytoin-treated mouse group was attenuated in the presence of lovastatin. This is related to the fact that statins, which are HMG-CoA reductase inhibitors, inhibit TGF-beta 1 expression in kidney and tooth extraction sockets [135].

\section{Adverse effects of statins as it pertains to oral health}

One study pertaining to statins and various oral health parameters was identified in this review. The article evaluated the side effects of statins in the oral cavity and characterized the symptoms after interruption of statin treatment.

Patients, aged 50-70 years old, who had been previously diagnosed with hypercholesterolemia and were receiving statin treatment were referred to a dentist's office. Anamnesis regarding their oral symptoms was obtained on their initial visit. Statin treatment was then discontinued, which was followed by various laboratory tests and repeat visits to the dentist at seven and 15 days after statin discontinuation. Results showed that a high percentage of oral symptoms included dry mouth, itchiness, bitterness, and cough during 
statin therapy. There was a marked improvement in their symptoms after temporary interruption of statin treatment. This study included a relatively small number of patients and a more thorough and detailed design of experimental treatments is needed to establish a true correlation between statin treatment and oral symptoms [139].

\section{Conclusion}

The studies reviewed in the present manuscript, while being heterogeneous in terms of the type of studies, interventional approaches, and the duration and intensity of intervention, overwhelmingly suggest that the statin family of drugs have unique beneficial effects on dental and oral health. Almost all of the studies, using different methodological approaches including observational, in vivo, in vitro, animal, and randomized clinical studies, showed that systemic and, in particular, local application of statins, plays a salient role in improving dental and oral health (Table 2).

Based on the results of this comprehensive review, it is suggested that statins possess a remarkable beneficial effect on chronic periodontitis, alveolar bone loss, osseointegration of implants, dental pulp cells, orthodontic tooth movement and subsequent relapse, tissue healing (wound/bone healing), and salivary gland function, as well as exhibiting anti-cancer properties in the oral cavity (Fig. 2). The findings of systematic reviews and meta-analyses contained in the current review confirm the favorable effects of statins on different aspects of dental and oral health (Table 1). Presently, there are several clinical trials underway to assess the therapeutic effects of statins on dental and overall oral health, especially as it relates to periodontitis (Table 3). In the future, it is strongly suggested that larger clinical trials be conducted to assess the pleiotropic effects of statins on dental and oral health, focusing on determination of the

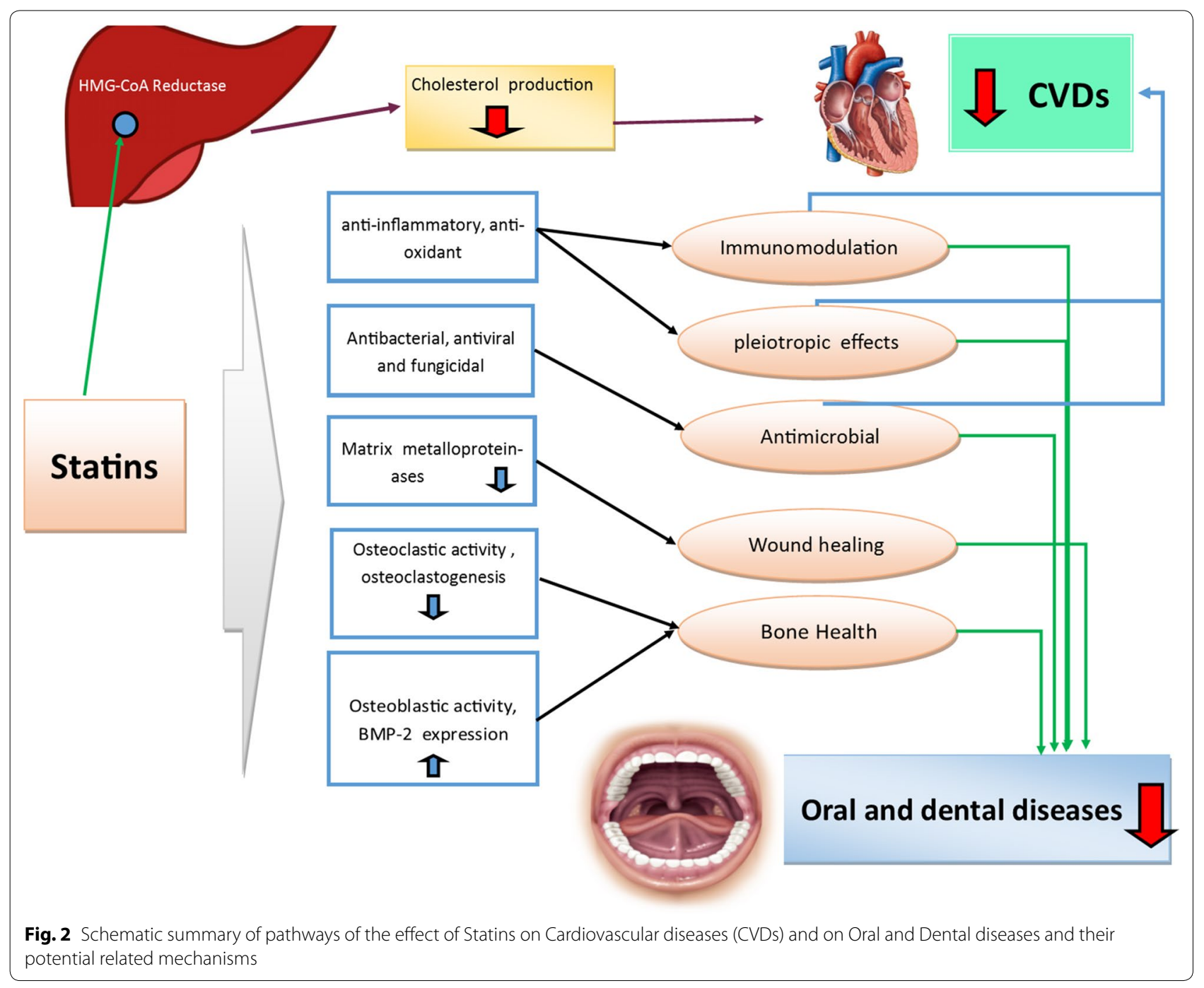




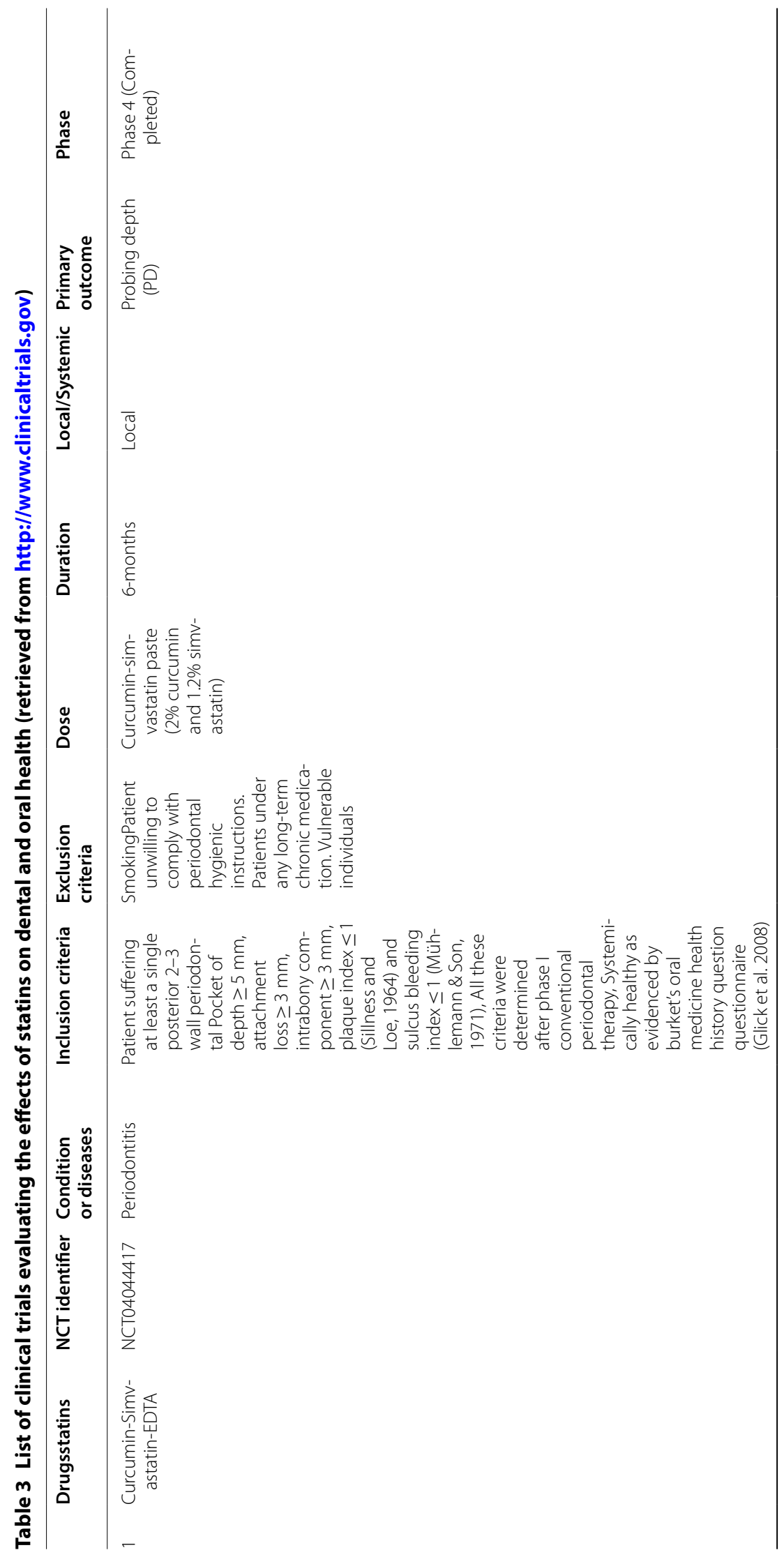




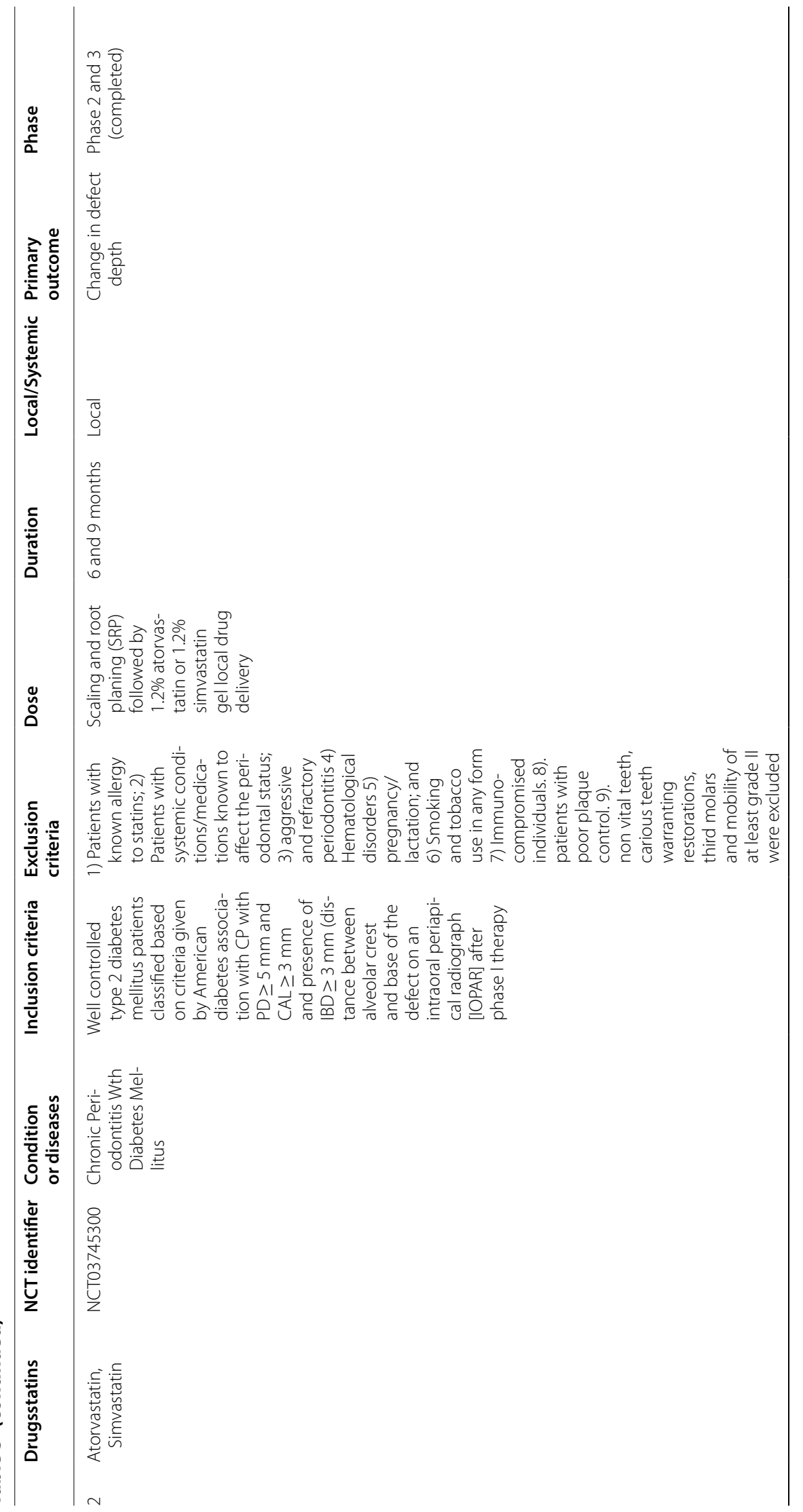




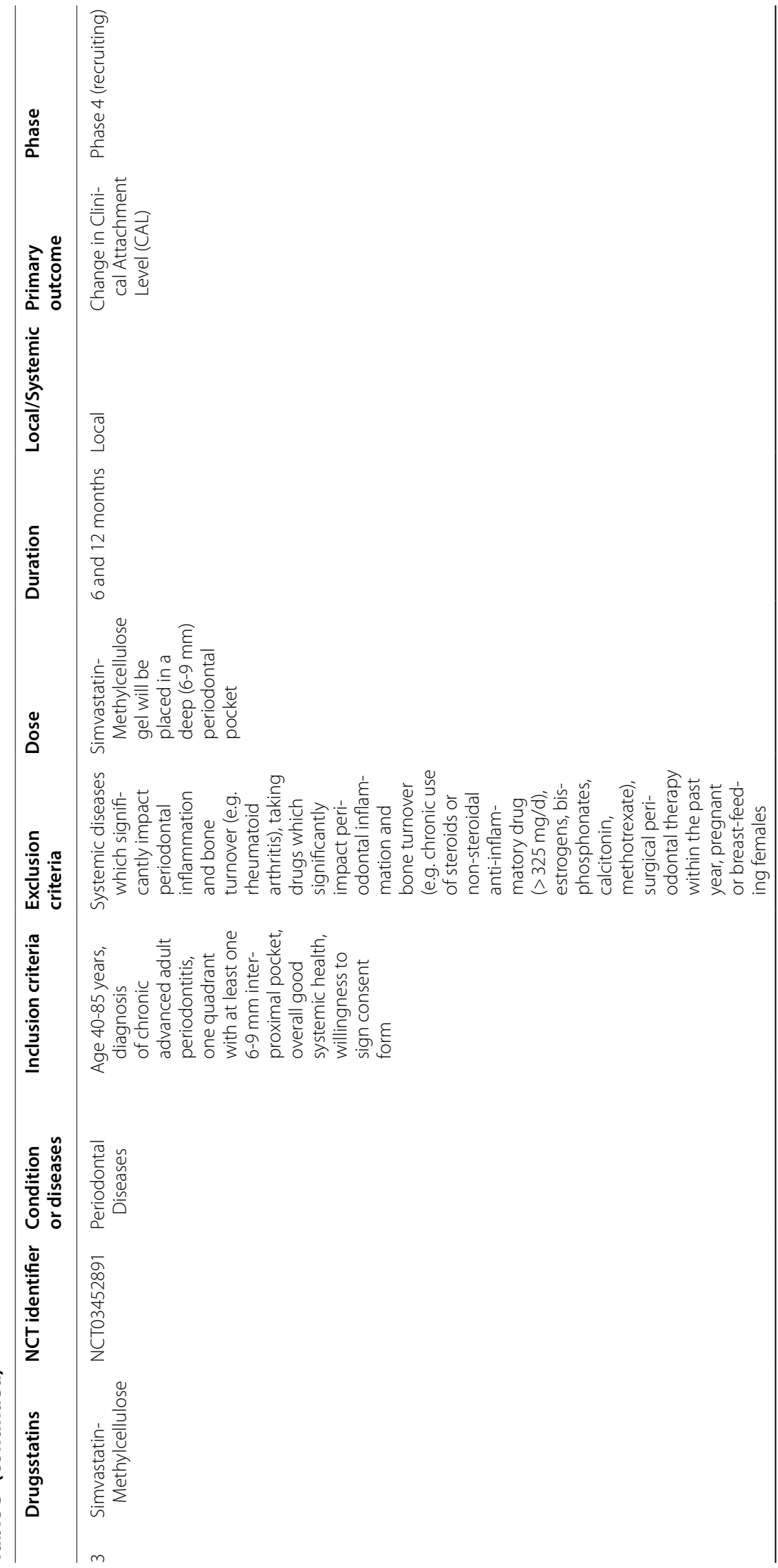




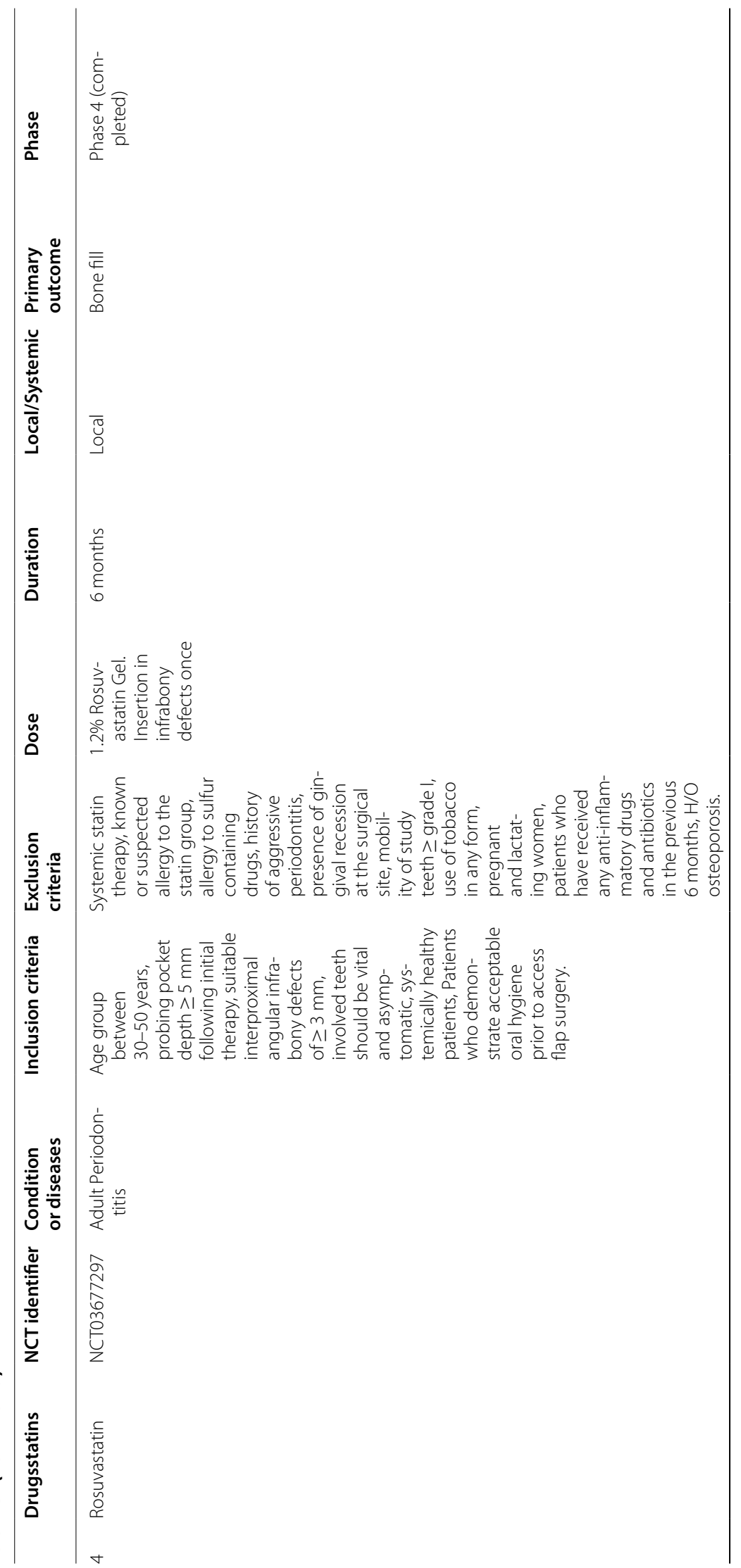




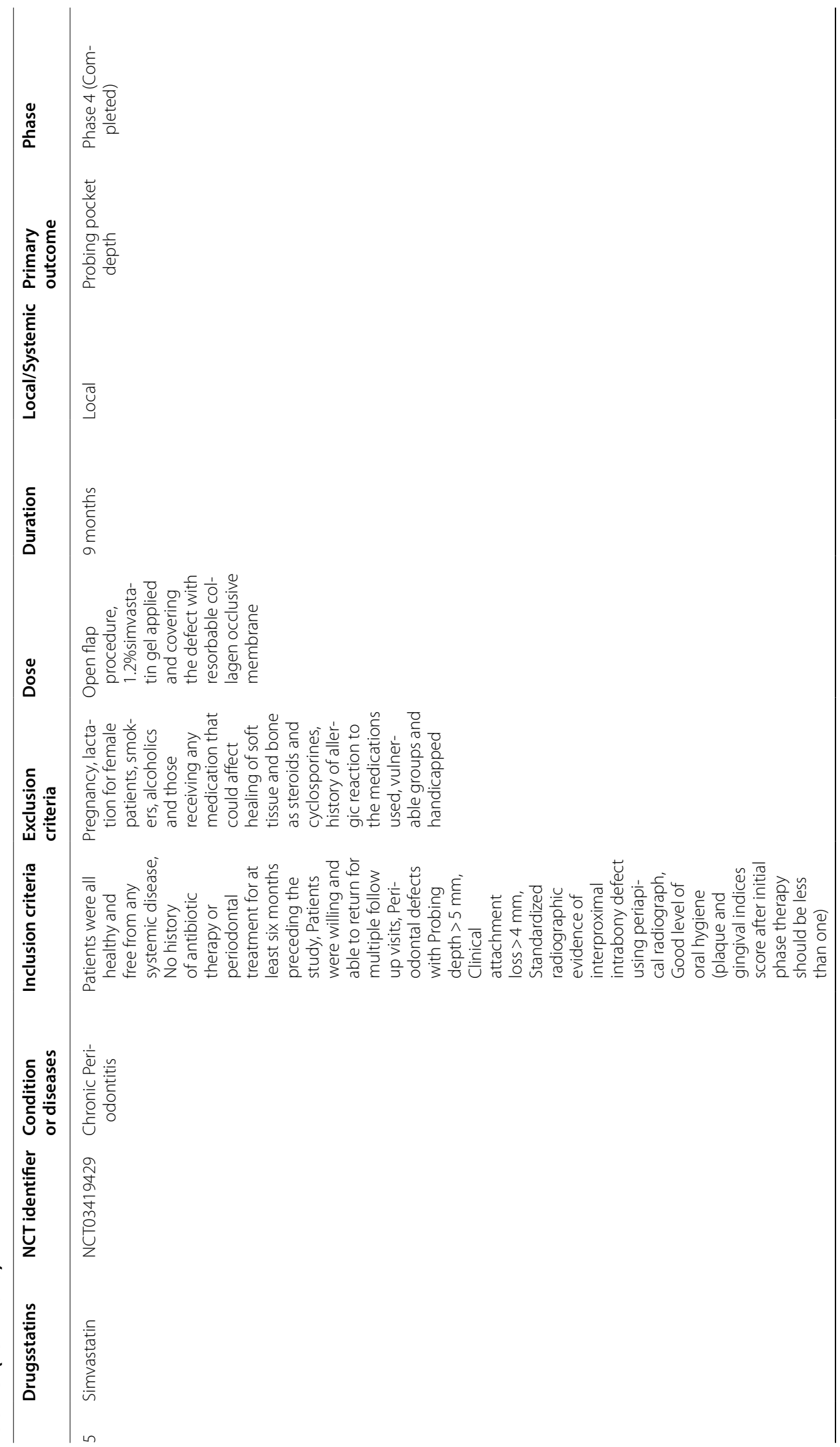




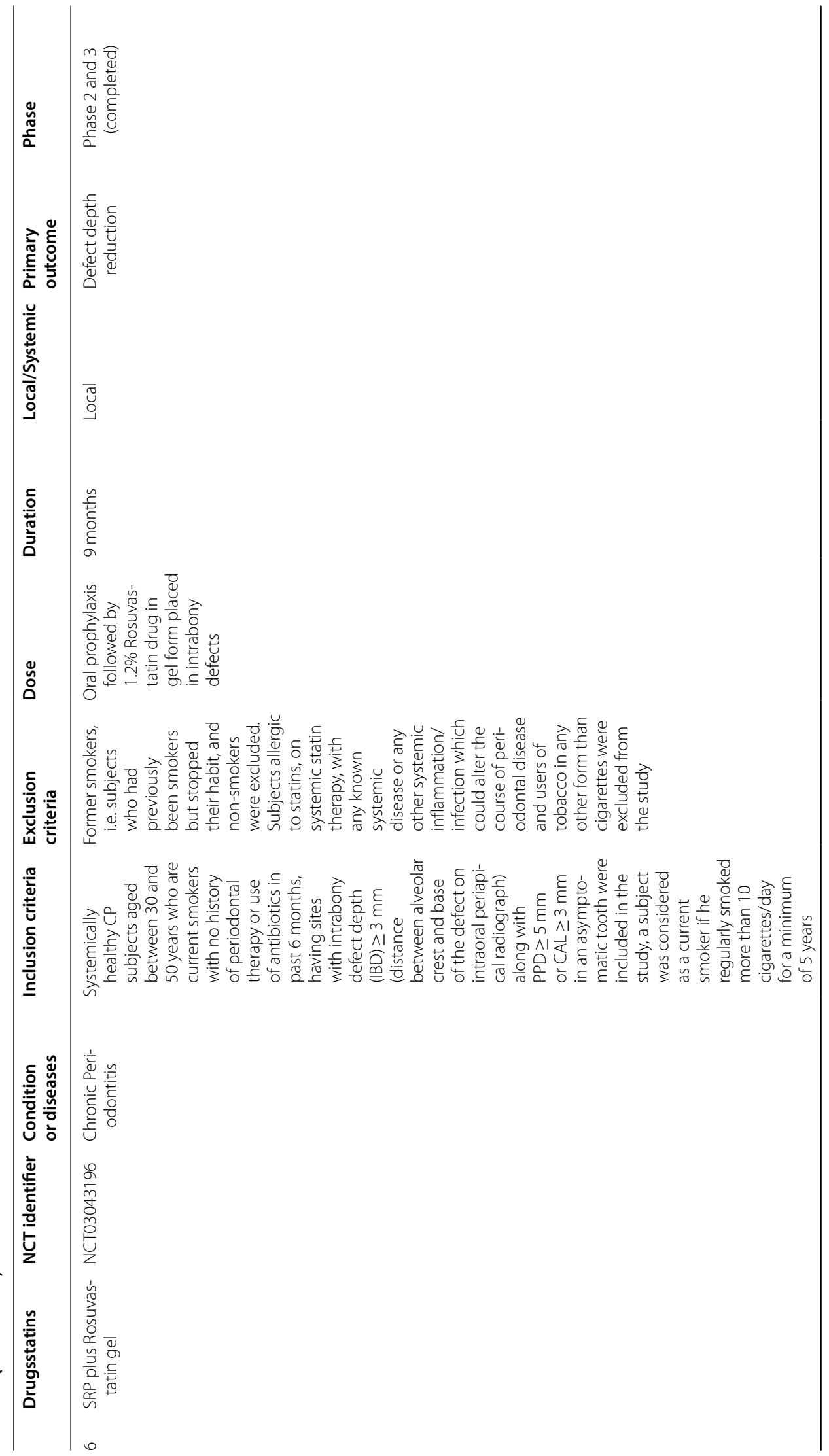




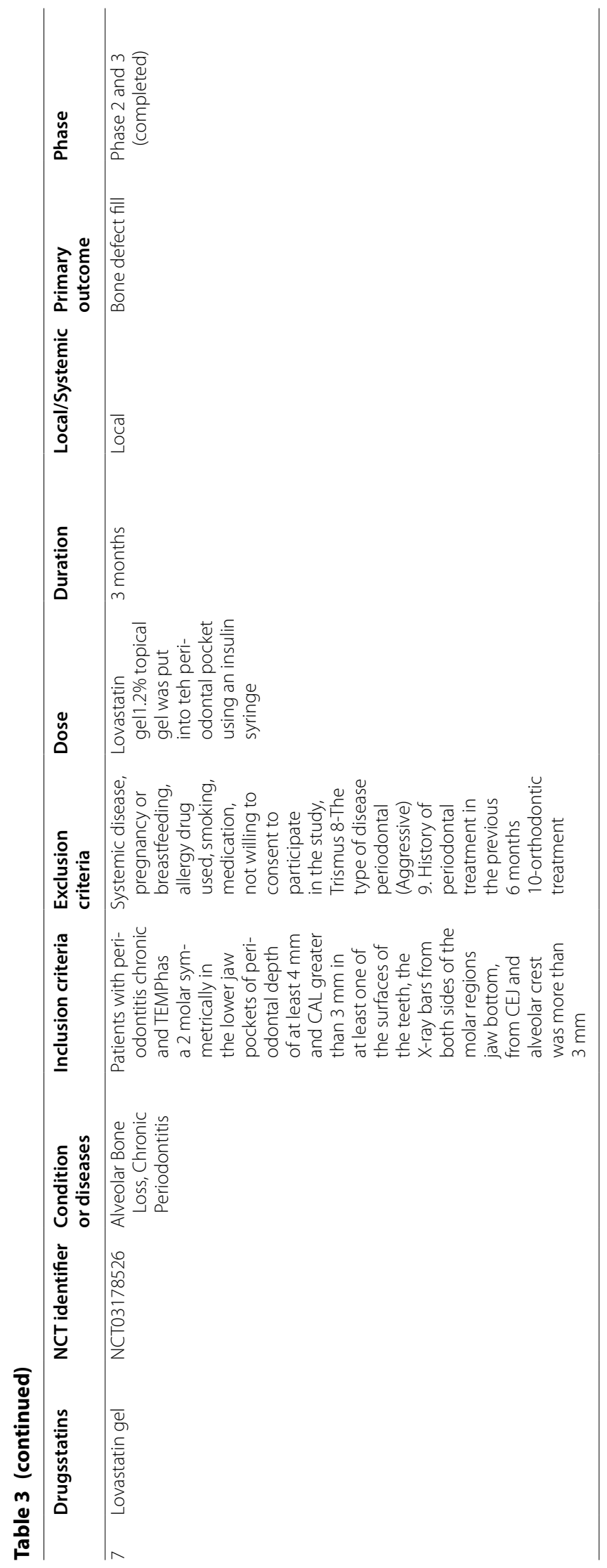


ideal duration, dose, and specific statin (atorvastatin, fluvastatin, lovastatin, rosuvastatin, or simvastatin) for the treatment of each particular dental and/or oral condition. However, in the meantime, and based on the findings contained in the present review, it is probably safe to suggest that local, or even systemic use of statins, should be considered as a novel, safe, inexpensive, and very accessible therapeutic agent with which to improve various aspects of overall dental and oral health.

\begin{abstract}
Abbreviations
HIV/AIDS: Human immunodeficiency virus/acquired immunodeficiency syndrome; NHANES: National Health and Nutrition Examination Survey; CVD: Cardiovascular disease; HMG-CoA: 3-hydroxy-3-methylglutaryl reductase A; LDL-C: Low-density lipoprotein cholesterol; BMP-2: Bone morphogenic protein-2; RANK: Receptor activator of nuclear kappa B; RANKL: Receptor activator of nuclear kappa B ligand; OPG: Osteoprotegerin; CRP: C-reactive protein; MMPs: Matrix metalloproteinases; SRP: Scaling and root planning; OTM: Orthodontic tooth movement; CAL: Clinical attachment level; PD: Pocket depth; RDD: Radiographic defect depth; ACP: Acute/chronified periodontal defects; PLGA: Poly-lactic-co-glycolic acid; HA: Hydroxyapatite; CO: Carbonate apatite; TGF-B1: Transforming growth factor B1; VEGF: Vascular endothelial growth factor; Micro-CT: Micro-computed tomography; CBCT: Cone beam computed tomography; LPS: Lipopolysaccharide; ATV: Atorvastatin; ABL: Alveolar bone loss; ALD: Alendronate; NBF: New bone formation; PGA: Propylene glycol alginate; MBV: Mineralized bone volume; BIC: Bone-implant contact; BCR: Bone contact ratio; BD: Bone density; MTA: Mineral trioxide aggregate; ALP: Alkaline phosphatase; DSSP: Dentin sialophosphoprotein; DMP1: Dentin matrix acidic phosphoprotein 1; OCN: Osteocalcin; DPSCs: Dental pulp stem cells; a-TCP: a-Tricalcium phosphate; HDPCS: Human dental pulp cells; TNF-a: Tumor necrosis factor-a; Cyr61: Cysteine-rich 61; CCL2: C-C Motif chemokine ligand 2; CMC: Carboxymethyl cellulose; PDL: Periodontal ligament; BMD: Bone mineral density; GI: Gingival index; SMV: Simvastatin; FGG: Free gingival graft; VAS: Visual analogue scale; RSV: Rosuvastatin; IR: Irradiation; miR-21i: MicroRNA-21 inhibitor; SACC-LM: Lung metastatic salivary adenoid cystic carcinoma; HNSCC: Head and neck squamous cell carcinoma; SCC: Squamous cell carcinoma; RhoC: Ras homolog gene family member C; ERK1/2: Extracellular signal-regulated Kinase 1/2; STAT3: Signal transducer and activator of transcription 3OM: Oral mucositis; 5-FU: 5-Xuorouracil.
\end{abstract}

\section{Acknowledgements}

Not applicable.

\section{Authors' contributions}

$\mathrm{AS}$ and $\mathrm{MB}$ contributed to the conception of this manuscript. All authors were responsible for the literature review, drafting and revision of the manuscript. All authors read and approved the final manuscript.

\section{Funding}

None.

\section{Availability of data and materials}

Not applicable.

\section{Ethics approval and consent to participate}

Not applicable.

\section{Consent for publication}

Not applicable.

\section{Competing interests}

The authors declare that they have no competing interests.

\section{Author details}

1 Dental Research Center, Department of Orthodontics, Dental Research Institute, Isfahan University of Medical Sciences, Isfahan, Iran. ${ }^{2}$ Department of Community Nutrition, School of Nutrition and Food Science, Food Security Research Center, Isfahan University of Medical Sciences, Isfahan, Iran. ${ }^{3}$ Division of Pharmacology and Pharmaceutical Sciences, School of Pharmacy, University of Missouri-Kansas City, Kansas City, MO, USA. ${ }^{4}$ Halal Research Center of IRI, FDA, Tehran, Iran. ${ }^{5}$ Neurogenic Inflammation Research Center, Mashhad University of Medical Sciences, Mashhad, Iran. ${ }^{6}$ Biotechnology Research Center, Pharmaceutical Technology Institute, Mashhad University of Medical Sciences, Mashhad, Iran. ${ }^{7}$ Department of Medical Biotechnology, School of Medicine, Mashhad University of Medical Sciences, P.O. Box: 91779-48564 Mashhad, Iran.

Received: 25 January 2020 Accepted: 1 April 2020

Published online: 06 April 2020

\section{References}

1. Petersen PE. The World oral health report 2003: continuous improvement of oral health in the 21st century-the approach of the WHO Global Oral Health Programme. Community Dent Oral Epidemiol. 2003;31(Suppl 1):3-23.

2. Petersen $P E$, Bourgeois $D$, Bratthall $D$, Ogawa $H$. Oral health information systems-towards measuring progress in oral health promotion and disease prevention. Bull World Health Organ. 2005;83:686-93.

3. Petersen PE, Bourgeois D, Ogawa H, Estupinan-Day S, Ndiaye C. The global burden of oral diseases and risks to oral health. Bull World Health Organ. 2005;83:661-9.

4. Righolt AJ, Jevdjevic M, Marcenes W, Listl S. Global-, regional-, and country-level economic impacts of dental diseases in 2015. J Dent Res. 2018:97:501-7.

5. Nazir MA. Prevalence of periodontal disease, its association with systemic diseases and prevention. Int J Health Sci. 2017;11:72-80.

6. Bergstrom J. Smoking rate and periodontal disease prevalence: 40-year trends in Sweden 1970-2010. J Clin Periodontol. 2014:41:952-7.

7. Casanova L, Hughes FJ, Preshaw PM. Diabetes and periodontal disease: a two-way relationship. Br Dent J. 2014;217:433-7.

8. Rai B, Kaur J, Anand SC, Jacobs R. Salivary stress markers, stress, and periodontitis: a pilot study. J Periodontol. 2011;82:287-92.

9. Scully C. Drug effects on salivary glands: dry mouth. Oral Dis. 2003:9:165-76.

10. Ide M, Papapanou PN. Epidemiology of association between maternal periodontal disease and adverse pregnancy outcomes-systematic review. J Periodontol. 2013;84:S181-94.

11. Martinez-Herrera M, Silvestre-Rangil J, Silvestre FJ. Association between obesity and periodontal disease. A systematic review of epidemiological studies and controlled clinical trials. Med Oral Patol Oral Cir Bucal. 2017;22:708-15.

12. Peng J, Song J, Han J, Chen Z, Yin X, Zhu J, Song J. The relationship between tooth loss and mortality from all causes, cardiovascular diseases, and coronary heart disease in the general population: systematic review and dose-response meta-analysis of prospective cohort studies. Biosci Rep. 2019. https://doi.org/10.1042/BSR20181773.

13. Teshome A, Yitayeh A. The effect of periodontal therapy on glycemic control and fasting plasma glucose level in type 2 diabetic patients: systematic review and meta-analysis. BMC Oral Health. 2016;17:31.

14. Ridker PM, Cook NR. Statins: new American guidelines for prevention of cardiovascular disease. Lancet. 2013;382:1762-5.

15. Lefer AM, Scalia R, Lefer DJ. Vascular effects of HMG CoA-reductase inhibitors (statins) unrelated to cholesterol lowering: new concepts for cardiovascular disease. Cardiovasc Res. 2001;49:281-7.

16. Zhou Q, Liao JK. Statins and cardiovascular diseases: from cholesterol lowering to pleiotropy. Curr Pharm Des. 2009;15:467-78.

17. Rauch U, Osende J, Chesebro J, Fuster V, Vorchheimer D, Harris K, Harris P, Sandler D, Fallon J, Jayaraman S. Statins and cardiovascular diseases: the multiple effects of lipid-lowering therapy by statins. Atherosclerosis. 2000;153:181-9.

18. Taylor F, Ward K, Moore TH, Burke M, Smith GD, Casas JP, Ebrahim S. Statins for the primary prevention of cardiovascular disease. Cochrane Database Syst Rev. 2011;15(1):17-29.

19. Shitara Y, Sugiyama Y. Pharmacokinetic and pharmacodynamic alterations of 3-hydroxy-3-methylglutaryl coenzyme A (HMG-CoA) reductase inhibitors: drug-drug interactions and interindividual differences 
in transporter and metabolic enzyme functions. Pharmacol Ther. 2006;112:71-105.

20. Stancu C, Sima A. Statins: mechanism of action and effects. J Cell Mol Med. 2001;5:378-87.

21. Glynn RJ, Danielson E, Fonseca FA, Genest J, Gotto AM Jr, Kastelein JJ, Koenig W, Libby P, Lorenzatti AJ, MacFadyen JG, et al. A randomized trial of rosuvastatin in the prevention of venous thromboembolism. N Engl J Med. 2009;360:1851-61.

22. Jain MK, Ridker PM. Anti-inflammatory effects of statins: clinical evidence and basic mechanisms. Nat Rev Drug Discov. 2005;4:977-87.

23. Pinal-Fernandez I, Casal-Dominguez M, Mammen AL. Statins: pros and cons. Med Clin (Barc). 2018;150:398-402.

24. Mundy G, Garrett R, Harris S, Chan J, Chen D, Rossini G, Boyce B, Zhao $M$, Gutierrez G. Stimulation of bone formation in vitro and in rodents by statins. Science. 1999;286:1946-9.

25. Chruściel P, Sahebkar A, Rembek-Wieliczko M, Serban MC, Ursoniu S, Mikhailidis DP, Jones SR, Mosteoru S, Blaha MJ, Martin SS, et al. Impact of statin therapy on plasma adiponectin concentrations: a systematic review and meta-analysis of 43 randomized controlled trial arms. Atherosclerosis. 2016:253:194-208.

26. Parizadeh SMR, Azarpazhooh MR, Moohebati M, Nematy M, Ghayour-Mobarhan M, Tavallaie S, Rahsepar AA, Amini M, Sahebkar A, Mohammadi M, Ferns GAA. Simvastatin therapy reduces prooxidantantioxidant balance: results of a placebo-controlled cross-over trial. Lipids. 2011:46:333-40.

27. Sahebkar A, Kotani K, Serban C, Ursoniu S, Mikhailidis DP, Jones SR, Ray KK, Blaha MJ, Rysz J, Toth PP, et al. Statin therapy reduces plasma endothelin-1 concentrations: a meta-analysis of 15 randomized controlled trials. Atherosclerosis. 2015;241:433-42.

28. Sahebkar A, Serban C, Mikhailidis DP, Undas A, Lip GYH, Muntner P, Bittner V, Ray KK, Watts GF, Hovingh GK, et al. Association between statin use and plasma d-dimer levels: a systematic review and meta-analysis of randomised controlled trials. Thromb Haemost. 2015;114:546-57.

29. Sahebkar A, Serban C, Ursoniu S, Mikhailidis DP, Undas A, Lip GYH, Bittner V, Ray KK, Watts GF, Kees Hovingh G, et al. The impact of statin therapy on plasma levels of von Willebrand factor antigen: systematic review and meta-analysis of Randomised placebo-controlled trials. Thromb Haemost. 2016;115:520-32.

30. Ruan F, Zheng Q, Wang J. Mechanisms of bone anabolism regulated by statins. Biosci Rep. 2012;32:511-9.

31. Uzzan B, Cohen R, Nicolas P, Cucherat M, Perret GY. Effects of statins on bone mineral density: a meta-analysis of clinical studies. Bone. 2007:40:1581-7.

32. Bertl K, Parllaku A, Pandis N, Buhlin K, Klinge B, Stavropoulos A. The effect of local and systemic statin use as an adjunct to non-surgical and surgical periodontal therapy-A systematic review and metaanalysis. J Dent. 2017;67:18-28.

33. Zhang Y, Bradley AD, Wang D, Reinhardt RA. Statins, bone metabolism and treatment of bone catabolic diseases. Pharmacol Res. 2014:88:53-61.

34. Jia W, Zhao Y, Yang J, Wang W, Wang X, Ling L, Ge L. Simvastatin promotes dental pulp stem cell-induced coronal pulp regeneration in pulpotomized teeth. J Endod. 2016;42:1049-54.

35. Lin HP, Tu HP, Hsieh YP, Lee BS. Controlled release of lovastatin from poly(lactic-co-glycolic acid) nanoparticles for direct pulp capping in rat teeth. Int J Nanomed. 2017;12:5473-85.

36. Pettiette MT, Zhong S, Moretti AJ, Khan AA. Potential correlation between statins and pulp chamber calcification. J Endod. 2013:39:1119-23.

37. Islam M, Sharma S, Kumar B, Teknos TN. Atorvastatin inhibits RhoC function and limits head and neck cancer metastasis. Oral Oncol. 2013;49:778-86.

38. Ma L, Niknejad N, Gorn-Hondermann I, Dayekh K, Dimitroulakos J. Lovastatin induces multiple stress pathways including LKB1/AMPK activation that regulate its cytotoxic effects in squamous cell carcinoma cells. PLoS ONE. 2012;7:e46055.

39. Bitto A, Minutoli L, Altavilla D, Polito F, Fiumara T, Marini H, Galeano M, Calo M, Lo Cascio P, Bonaiuto M, et al. Simvastatin enhances VEGF production and ameliorates impaired wound healing in experimental diabetes. Pharmacol Res. 2008:57:159-69.
40. Rego AC, Araujo Filho I, Damasceno BP, Egito ES, Silveira IA, BrandaoNeto J, Medeiros AC. Simvastatin improves the healing of infected skin wounds of rats. Acta Cir Bras. 2007;22(Suppl 1):57-63.

41. Emani S, Gunjiganur GV, Mehta DS. Determination of the antibacterial activity of simvastatin against periodontal pathogens, Porphyromonas gingivalis and Aggregatibacter actinomycetemcomitans: an in vitro study. Contemp Clin Dent. 2014;5:377-82.

42. Masadeh M, Mhaidat N, Alzoubi K, Al-Azzam S, Alnasser Z. Antibacterial activity of statins: a comparative study of atorvastatin, simvastatin, and rosuvastatin. Ann Clin Microbiol Antimicrob. 2012;11:13.

43. Akram Z, Vohra F, Javed F. Efficacy of statin delivery as an adjunct to scaling and root planing in the treatment of chronic periodontitis: a meta-analysis. J Investig Clin Dent. 2018;9:e12304.

44. Bertl K, Steiner I, Pandis N, Buhlin K, Klinge B, Stavropoulos A. Statins in nonsurgical and surgical periodontal therapy. A systematic review and meta-analysis of preclinical in vivo trials. J Periodontal Res. 2018;53:267-87.

45. Garrett IR, Mundy GR. The role of statins as potential targets for bone formation. Arthritis Res. 2002;4:237-40.

46. Maritz FJ, Conradie MM, Hulley PA, Gopal R, Hough S. Effect of statins on bone mineral density and bone histomorphometry in rodents. Arterioscler Thromb Vasc Biol. 2001;21:1636-41.

47. Kellesarian SV, Al Amri MD, Al-Kheraif AA, Ghanem A, Malmstrom H, Javed F. Efficacy of local and systemic statin delivery on the osseointegration of implants: a systematic review. Int J Oral Maxillofac Implants. 2017:32:497-506.

48. Estanislau IM, Terceiro IR, Lisboa MR, Teles Pde B, Carvalho Rde S, Martins RS, Moreira MM. Pleiotropic effects of statins on the treatment of chronic periodontitis-a systematic review. Br J Clin Pharmacol. 2015;79:877-85

49. Meza-Mauricio J, Soto-Penaloza D, Penarrocha-Oltra D, Montiel-Company JM, Peruzzo DC. Locally applied statins as adjuvants to non-surgical periodontal treatment for chronic periodontitis: a systematic review and meta-analysis. Clin Oral Investig. 2018;22:2413-30.

50. Muniz F, Taminski K, Cavagni J, Celeste RK, Weidlich P, Rosing CK. The effect of statins on periodontal treatment-a systematic review with meta-analyses and meta-regression. Clin Oral Investig. 2018;22:671-87.

51. Ting M, Whitaker EJ, Albandar JM. Systematic review of the in vitro effects of statins on oral and perioral microorganisms. Eur J Oral Sci. 2016;124:4-10.

52. Arnaud C, Burger F, Steffens S, Veillard NR, Nguyen TH, Trono D, Mach F. Statins reduce interleukin-6-induced $\mathrm{C}$-reactive protein in human hepatocytes: new evidence for direct antiinflammatory effects of statins. Arterioscler Thromb Vasc Biol. 2005;25:1231-6.

53. Lin SK, Kok SH, Lee YL, Hou KL, Lin YT, Chen MH, Wang CC, Hong CY. Simvastatin as a novel strategy to alleviate periapical lesions. J Endod. 2009;35:657-62.

54. Paumelle R, Blanquart C, Briand O, Barbier O, Duhem C, Woerly G, Percevault F, Fruchart JC, Dombrowicz D, Glineur C, Staels B. Acute antiinflammatory properties of statins involve peroxisome proliferatoractivated receptor-alpha via inhibition of the protein kinase $\mathrm{C}$ signaling pathway. Circ Res. 2006;98:361-9.

55. Sakoda K, Yamamoto M, Negishi Y, Liao JK, Node K, Izumi Y. Simvastatin decreases IL-6 and IL-8 production in epithelial cells. J Dent Res. 2006:85:520-3.

56. Liu S, Bertl K, Sun H, Liu ZH, Andrukhov O, Rausch-Fan X. Effect of simvastatin on the osteogenetic behavior of alveolar osteoblasts and periodontal ligament cells. Hum Cell. 2012;25:29-35.

57. Maeda T, Kawane T, Horiuchi N. Statins augment vascular endothelial growth factor expression in osteoblastic cells via inhibition of protein prenylation. Endocrinology. 2003;144:681-92.

58. Viereck V, Grundker C, Blaschke S, Frosch KH, Schoppet M, Emons G, Hofbauer LC. Atorvastatin stimulates the production of osteoprotegerin by human osteoblasts. J Cell Biochem. 2005;96:1244-53.

59. Davignon J, Laaksonen R. Low-density lipoprotein-independent effects of statins. Curr Opin Lipidol. 1999:10:543-59.

60. Luan Z, Chase AJ, Newby AC. Statins inhibit secretion of metalloproteinases-1, $-2,-3$, and -9 from vascular smooth muscle cells and macrophages. Arterioscler Thromb Vasc Biol. 2003;23:769-75. 
61. Poston CJ, Pierce TC, Li Y, Brinson CW, Lu Z, Lauer AW, Leite RS, Huang Y. Statin intake is associated with MMP-1 level in gingival crevicular fluid of patients with periodontitis. Oral Dis. 2016;22:438-44.

62. Park A, Barrera-Ramirez J, Ranasinghe I, Pilon S, Sy R, Fergusson D, Allan DS. Use of statins to augment progenitor cell function in preclinical and clinical studies of regenerative therapy: a systematic review. Stem Cell Rev Rep. 2016;12:327-39.

63. Shah SR, Werlang CA, Kasper FK, Mikos AG. Novel applications of statins for bone regeneration. Natl Sci Rev. 2015;2:85-99.

64. Song C, Guo Z, Ma Q, Chen Z, Liu Z, Jia H, Dang G. Simvastatin induces osteoblastic differentiation and inhibits adipocytic differentiation in mouse bone marrow stromal cells. Biochem Biophys Res Commun. 2003:308:458-62.

65. Staal A, Frith JC, French MH, Swartz J, Gungor T, Harrity TW, Tamasi J, Rogers MJ, Feyen $\mathrm{JH}$. The ability of statins to inhibit bone resorption is directly related to their inhibitory effect on $\mathrm{HMG}-\mathrm{CoA}$ reductase activity. J Bone Miner Res. 2003;18:88-96.

66. Noronha Oliveira M, Rau LH, Marodin A, Correa M, Correa LR, Aragones A, Magini RS. Ridge preservation after maxillary third molar extraction using 30\% porosity PLGA/HA/beta-TCP scaffolds with and without simvastatin: a pilot randomized controlled clinical trial. Implant Dent. 2017;26:832-40.

67. Rakhmatia YD, Ayukawa Y, Furuhashi A, Koyano K. Carbonate apatite containing statin enhances bone formation in healing incisal extraction sockets in rats. Materials (Basel). 2018;11(7):1201.

68. Sezavar M, Bohlouli B, Farhadi S, Tabatabaee S, Latifi R. Simvastatin effects on dental socket quality: a comparative study. Contemp Clin Dent. 2018;9:55-9.

69. Liu C, Wu Z, Sun HC. The effect of simvastatin on mRNA expression of transforming growth factor-beta1, bone morphogenetic protein-2 and vascular endothelial growth factor in tooth extraction socket. Int J Oral Sci. 2009;1:90-8.

70. Wu Z, Liu C, Zang G, Sun H. The effect of simvastatin on remodelling of the alveolar bone following tooth extraction. Int J Oral Maxillofac Surg. 2008:37:170-6.

71. de Mones E, Schlaubitz S, Catros S, Fricain JC. Statins and alveolar bone resorption: a narrative review of preclinical and clinical studies. Oral Surg Oral Med Oral Pathol Oral Radiol. 2015;119:65-73.

72. Goes P, Lima AP, Melo IM, Rego RO, Lima V. Effect of Atorvastatin in radiographic density on alveolar bone loss in wistar rats. Braz Dent J. 2010;21:193-8.

73. Goes P, Lima NA, Rodrigues JA, Benevides NM, Brito GA, Lima V. Antiinflammatory and Anti-resorptive effects of Atorvastatin on alveolar bone loss in Wistar Rats. Braz Dent J. 2016;27:267-72.

74. Goes P, Melo IM, Silva LM, Benevides NM, Alencar NM, Ribeiro RA, Lima V. Low-dose combination of alendronate and atorvastatin reduces ligature-induced alveolar bone loss in rats. J Periodontal Res. 2014;49:45-54.

75. Nassar PO, Nassar CA, Guimaraes MR, Aquino SG, Andia DC, Muscara MN, Spolidorio DM, Rossa C Jr, Spolidorio LC. Simvastatin therapy in cyclosporine A-induced alveolar bone loss in rats. J Periodontal Res. 2009;44:479-88

76. Pokhrel NK, Kim YG, Kim JY, Kim HH, Lee Y. Fluvastatin inhibits osteoclast differentiation and Porphyromonas gingivalis LipopolysaccharideInduced alveolar bone erosion in mice. J Periodontol. 2017:88:390-8.

77. Seto H, Ohba H, Tokunaga K, Hama H, Horibe M, Nagata T. Topical administration of simvastatin recovers alveolar bone loss in rats. J Periodontal Res. 2008:43:261-7.

78. Tanigo T, Takaoka R, Tabata Y. Sustained release of water-insoluble simvastatin from biodegradable hydrogel augments bone regeneration. Control Release. 2010;143:201-6.

79. Tan WL, Wong TL, Wong MC, Lang NP. A systematic review of postextractional alveolar hard and soft tissue dimensional changes in humans. Clin Oral Implants Res. 2012;23(Suppl 5):1-21.

80. Price U, Le HO, Powell SE, Schmid MJ, Marx DB, Zhang Y, Wang D, Narayana N, Reinhardt RA. Effects of local simvastatin-alendronate conjugate in preventing periodontitis bone loss. J Periodontal Res. 2013;48:541-8.

81. Dalcico R, de Menezes AM, Deocleciano OB, Oria RB, Vale ML, Ribeiro RA, Brito GA. Protective mechanisms of simvastatin in experimental periodontal disease. J Periodontol. 2013;84:1145-57.
82. Fajardo ME, Rocha ML, Sanchez-Marin FJ, Espinosa-Chavez EJ. Effect of atorvastatin on chronic periodontitis: a randomized pilot study. J Clin Periodontol. 2010:37:1016-22

83. Jin J, Machado ER, Yu H, Zhang X, Lu Z, Li Y, Lopes-Virella MF, Kirkwood KL, Huang Y. Simvastatin inhibits LPS-induced alveolar bone loss during metabolic syndrome. J Dent Res. 2014;93:294-9.

84. Jin J, Zhang X, Lu Z, Li Y, Lopes-Virella MF, Yu H, Haycraft CJ, Li O Kirkwood KL, Huang Y. Simvastatin inhibits lipopolysaccharide-induced osteoclastogenesis and reduces alveolar bone loss in experimental periodontal disease. J Periodontal Res. 2014;49:518-26.

85. Machado WM, Prestes AP, Costa TP, Mendes RT, Olchanheski LR Jr, Sordi R, Otuki MF, Favero GM, Vellosa JC, Santos FA, Fernandes D. The effect of simvastatin on systemic inflammation and endothelial dysfunction induced by periodontitis. J Periodontal Res. 2014:49:634-41.

86. Nassar CA, Battistetti GD, Nahsan FP, Olegario J, Marconato J, Marin CF, Faccioni DM, da Costa KF, Kottwitz LB, Nassar PO. Evaluation of the effect of simvastatin on the progression of alveolar bone loss in experimental periodontitis-an animal study. J Int Acad Periodontol. 2014;16:2-7.

87. Sundararaj SC, Thomas MV, Peyyala R, Dziubla TD, Puleo DA. Design of a multiple drug delivery system directed at periodontitis. Biomaterials. 2013;34:8835-42.

88. Pradeep AR, Priyanka N, Kalra N, Naik SB, Singh SP, Martande S. Clinical efficacy of subgingivally delivered 1.2-mg simvastatin in the treatment of individuals with class II furcation defects: a randomized controlled clinical trial. J Periodontol. 2012;83:1472-9.

89. Pradeep AR, Rao NS, Bajaj P, Kumari M. Efficacy of subgingivally delivered simvastatin in the treatment of patients with type 2 diabetes and chronic periodontitis: a randomized double-masked controlled clinical trial. J Periodontol. 2013;84:24-31.

90. Pradeep AR, Thorat MS. Clinical effect of subgingivally delivered simvastatin in the treatment of patients with chronic periodontitis: a randomized clinical trial. J Periodontol. 2010;81:214-22.

91. Fu JH, Bashutski JD, Al-Hezaimi K, Wang HL. Statins, glucocorticoids, and nonsteroidal anti-inflammatory drugs: their influence on implant healing. Implant Dent. 2012:21:362-7.

92. Moraschini V, Almeida DCF, Calasans-Maia JA, Diuana Calasans-Maia $M$. The ability of topical and systemic statins to increase osteogenesis around dental implants: a systematic review of histomorphometric outcomes in animal studies. Int J Oral Maxillofac Surg. 2018:47:1070-8.

93. Moriyama Y, Ayukawa Y, Ogino Y, Atsuta I, Koyano K. Topical application of statin affects bone healing around implants. Clin Oral Implants Res. 2008;19:600-5

94. Moriyama Y, Ayukawa Y, Ogino Y, Atsuta I, Todo M, Takao Y, Koyano K. Local application of fluvastatin improves peri-implant bone quantity and mechanical properties: a rodent study. Acta Biomater. 2010;6:1610-8.

95. Ayukawa Y, Okamura A, Koyano K. Simvastatin promotes osteogenesis around titanium implants. Clin Oral Implants Res. 2004;15:346-50.

96. Ayukawa Y, Ogino Y, Moriyama Y, Atsuta I, Jinno Y, Kihara M, Tsukiyama Y, Koyano K. Simvastatin enhances bone formation around titanium implants in rat tibiae. J Oral Rehabil. 2010;37:123-30.

97. Basarir K, Erdemli B, Can A, Erdemli E, Zeyrek T. Osseointegration in arthroplasty: can simvastatin promote bone response to implants? Int Orthop. 2009:33:855-9.

98. Du Z, Chen J, Yan F, Xiao Y. Effects of Simvastatin on bone healing around titanium implants in osteoporotic rats. Clin Oral Implants Res. 2009:20:145-50

99. Tan J, Yang N, Fu X, Cui Y, Guo Q, Ma T, Yin X, Leng H, Song C. Singledose local simvastatin injection improves implant fixation via increased angiogenesis and bone formation in an ovariectomized rat model. Med Sci Monit. 2015:21:1428-39.

100. Masuzaki T, Ayukawa Y, Moriyama Y, Jinno Y, Atsuta I, Ogino Y, Koyano $K$. The effect of a single remote injection of statin-impregnated poly (lactic-co-glycolic acid) microspheres on osteogenesis around titanium implants in rat tibia. Biomaterials. 2010:31:3327-34.

101. Fang W, Zhao S, He F, Liu L, Yang G. Influence of simvastatin-loaded implants on osseointegration in an ovariectomized animal model. Biomed Res Int 2015:2015:831504. 
102. Giro G, Chambrone L, Goldstein A, Rodrigues JA, Zenobio E, Feres M, Figueiredo LC, Cassoni A, Shibli JA. Impact of osteoporosis in dental implants: a systematic review. World J Orthop. 2015;6:311-5.

103. Huang W, Shang WL, Li DH, Wu WW, Hou SX. Simvastatin protects osteoblast against $\mathrm{H} 2 \mathrm{O} 2$-induced oxidative damage via inhibiting the upregulation of Nox4. Mol Cell Biochem. 2012;360:71-7.

104. Alghofaily M, Tordik P, Romberg E, Martinho F, Fouad AF. Healing of apical periodontitis after nonsurgical root canal treatment: the role of statin intake. J Endod. 2018;44:1355-60.

105. Asl Aminabadi N, Maljaei E, Erfanparast L, Ala Aghbali A, Hamishehkar H, Najafpour E. Simvastatin versus calcium hydroxide direct pulp capping of human primary molars: a randomized clinical trial. J Dent Res Dent Clin Dent Prospects. 2013;7:8-14.

106. Varalakshmi PR, Kavitha M, Govindan R, Narasimhan S. Effect of statins with alpha-tricalcium phosphate on proliferation, differentiation, and mineralization of human dental pulp cells. J Endod. 2013;39:806-12.

107. AlSwafeeri H, ElKenany W, Mowafy M, Karam S. Effect of local administration of simvastatin on postorthodontic relapse in a rabbit model. Am J Orthod Dentofacial Orthop. 2018;153:861-71.

108. Dolci GS, Ballarini A, Gameiro GH, de Souza DO, de Melo F, Fossati AC. Atorvastatin inhibits osteoclastogenesis and arrests tooth movement. Am J Orthod Dentofacial Orthop. 2018;153:872-82.

109. Dolci GS, Portela LV, de Souza DO, de Medeiros Fossati AC. Atorvastatininduced osteoclast inhibition reduces orthodontic relapse. Am J Orthod Dentofacial Orthop. 2017;151:528-38.

110. Han G, Chen Y, Hou J, Liu C, Chen C, Zhuang J, Meng W. Effects of simvastatin on relapse and remodeling of periodontal tissues after tooth movement in rats. Am J Orthod Dentofacial Orthop. 2010;138:550.e551.

111. Jahanbin A, Abtahi M, Namdar P, Heravi F, Sadeghi F, Arab H, Shafaee $H$. Evaluation of the effects of subgingival injection of Simvastatin on space re-opening after orthodontic space closure in adults. J Dent Res Dent Clin Dent Prospects. 2016;10:3-7.

112. MirHashemi AH, Afshari M, Alaeddini M, Etemad-Moghadam S, Dehpour A, Sheikhzade S, Akhoundi MS. Effect of atorvastatin on orthodontic tooth movement in male wistar rats. J Dent. 2013;10:532-9.

113. Vieira GM, Chaves SB, Ferreira VM, Freitas KM, Amorim RF. The effect of simvastatin on relapse of tooth movement and bone mineral density in rats measured by a new method using microtomography. Acta Cir Bras. 2015;30:319-27.

114. AlSwafeeri H, ElKenany W, Mowafy M, Karam S. Effect of local administration of simvastatin on postorthodontic relapse in a rabbit model. Am J Orthod Dentofac Orthop. 2018:153:861-71.

115. Grasser WA, Baumann AP, Petras SF, Harwood HJ Jr, Devalaraja R, Renkiewicz R, Baragi V, Thompson DD, Paraklar VM. Regulation of osteoclast differentiation by statins. J Musculoskelet Neuronal Interact. 2003:3:53-62

116. Madi M, Kassem A. Topical simvastatin gel as a novel therapeutic modality for palatal donor site wound healing following free gingival graft procedure. Acta Odontol Scand. 2018;76:212-9.

117. Rutledge J, Schieber MD, Chamberlain JM, Byarlay M, Killeen AC, Giannini PJ, Marx DB, Reinhardt RA. Simvastatin application to augment facial jaw bone in a dog model: pilot study. J Periodontol. 2011:82:597-605.

118. Turer A, Durmuslar MC, Sener I, Misir AF, Onger ME. The effect of local rosuvastatin on Mandibular fracture healing. J Craniofac Surg. 2016;27:e758-61.

119. Asai J, Takenaka H, Hirakawa S, Sakabe J, Hagura A, Kishimoto S, Maruyama K, Kajiya K, Kinoshita S, Tokura Y, Katoh N. Topical simvastatin accelerates wound healing in diabetes by enhancing angiogenesis and lymphangiogenesis. Am J Pathol. 2012;181:2217-24.

120. Kureishi Y, Luo Z, Shiojima I, Bialik A, Fulton D, Lefer DJ, Sessa WC, Walsh $\mathrm{K}$. The HMG-CoA reductase inhibitor simvastatin activates the protein kinase Akt and promotes angiogenesis in normocholesterolemic animals. Nat Med. 2000;6:1004-10.

121. Mihos CG, Santana O. Pleiotropic effects of the HMG-CoA reductase inhibitors. Int J Gen Med. 2011;4:261-71.

122. Xu L, Yang X, Chen J, Ge X, Qin Q, Zhu H, Zhang C, Sun X. Simvastatin attenuates radiation-induced salivary gland dysfunction in mice. Drug Des Devel Ther. 2016;10:2271-8.
123. Cai WY, Zhuang Y, Yan F, Li T, Song WT, Sun JH. Effect of survivin downregulation by simvastatin on the growth and invasion of salivary adenoid cystic carcinoma. Mol Med Rep. 2018;18:1939-46.

124. Pavan LM, Rego DF, Elias ST, De Luca Canto G, Guerra EN. In vitro AntiTumor effects of statins on head and neck squamous cell Carcinoma: a systematic review. PLoS ONE. 2015;10:e0130476.

125. Wang C, Li T, Yan F, Cai W, Zheng J, Jiang X, Sun J. Effect of simvastatin and microRNA-21 inhibitor on metastasis and progression of human salivary adenoid cystic carcinoma. Biomed Pharmacother. 2018;105:1054-61.

126. Belcher R, Hayes K, Fedewa S, Chen AY. Current treatment of head and neck squamous cell cancer. J Surg Oncol. 2014;110:551-74.

127. Gabrys D, Dorfler A, Yaromina A, Hessel F, Krause M, Oertel R, Baumann $M$. Effects of lovastatin alone or combined with irradiation on tumor cells in vitro and in vivo. Strahlenther Onkol. 2008;184:48-53.

128. Mantha AJ, McFee KE, Niknejad N, Goss G, Lorimer IA, Dimitroulakos J. Epidermal growth factor receptor-targeted therapy potentiates lovastatin-induced apoptosis in head and neck squamous cell carcinoma cells. J Cancer Res Clin Oncol. 2003;129:631-41.

129. Mantha AJ, Hanson JE, Goss G, Lagarde AE, Lorimer IA, Dimitroulakos J. Targeting the mevalonate pathway inhibits the function of the epidermal growth factor receptor. Clin Cancer Res. 2005;11:2398-407.

130. Dayekh K, Johnson-Obaseki S, Corsten M, Villeneuve PJ, Sekhon HS, Weberpals Jl, Dimitroulakos J. Monensin inhibits epidermal growth factor receptor trafficking and activation: synergistic cytotoxicity in combination with EGFR inhibitors. Mol Cancer Ther. 2014;13:2559-71.

131. de Llobet LI, Baro M, Mesia R, Balart J. Simvastatin enhances the effects of radiotherapy and cetuximab on a cell line ( $\mathrm{FaDu}$ ) derived from a Ssquamous cell carcinoma of head and neck. Transl Oncol. 2014;7:513-22.

132. Niknejad N, Gorn-Hondermann I, Ma L, Zahr S, Johnson-Obeseki S, Corsten M, Dimitroulakos J. Lovastatin-induced apoptosis is mediated by activating transcription factor 3 and enhanced in combination with salubrinal. Int J Cancer. 2014;134:268-79.

133. Dimitroulakos J, Marhin WH, Tokunaga J, Irish J, Gullane P, Penn LZ, Kamel-Reid S. Microarray and biochemical analysis of lovastatininduced apoptosis of squamous cell carcinomas. Neoplasia. 2002:4:337-46.

134. Takeda I, Maruya S, Shirasaki T, Mizukami H, Takahata T, Myers JN, Kakehata S, Yagihashi S, Shinkawa H. Simvastatin inactivates beta 1-integrin and extracellular signal-related kinase signaling and inhibits cell proliferation in head and neck squamous cell carcinoma cells. Cancer Sci. 2007;98:890-9.

135. Assaggaf MA, Kantarci A, Sume SS, Trackman PC. Prevention of phenytoin-induced gingival overgrowth by lovastatin in mice. Am J Pathol. 2015:185:1588-99.

136. Medeiros CA, Leitao RF, Macedo RN, Barboza DR, Gomes AS, Nogueira NA, Alencar NM, Ribeiro RA, Brito GA. Effect of atorvastatin on 5-fluorouracil-induced experimental oral mucositis. Cancer Chemother Pharmacol. 2011;67:1085-100.

137. Hong HH, Uzel MI, Duan C, Sheff MC, Trackman PC. Regulation of lysyl oxidase, collagen, and connective tissue growth factor by TGF-beta1 and detection in human gingiva. Lab Invest. 1999;79:1655-67.

138. Uzel Ml, Kantarci A, Hong HH, Uygur C, Sheff MC, Firatli E, Trackman PC. Connective tissue growth factor in drug-induced gingival overgrowth. J Periodontol. 2001;72:921-31.

139. Pascual Cruz M, Chimenos Kustner E, Garcia Vicente JA, Mezquiriz Ferrero X, Borrell Thio E, Lopez Lopez J. Adverse side effects of statins in the oral cavity. Med Oral Patol Oral Cir Bucal. 2008;13:E98-101.

\section{Publisher's Note}

Springer Nature remains neutral with regard to jurisdictional claims in published maps and institutional affiliations. 